Article

\title{
Optimization of a High-Throughput 384-Well Plate-Based Screening Platform with Staphylococcus aureus ATCC 25923 and Pseudomonas aeruginosa ATCC 15442 Biofilms
}

\author{
Shella Gilbert-Girard ${ }^{1, *(\mathbb{D})}$, Kirsi Savijoki ${ }^{1}{ }^{\mathbb{D}}$, Jari Yli-Kauhaluoma ${ }^{2}{ }^{\mathbb{D}}$ and Adyary Fallarero ${ }^{1}$ \\ 1 Drug Research Program, Division of Pharmaceutical Biosciences, Faculty of Pharmacy, University of \\ Helsinki, FI-00014 Helsinki, Finland; kirsi.savijoki@helsinki.fi (K.S.); adyary.fallarero@helsinki.fi (A.F.) \\ 2 Drug Research Program, Division of Pharmaceutical Chemistry and Technology, Faculty of Pharmacy, \\ University of Helsinki, FI-00014 Helsinki, Finland; jari.yli-kauhaluoma@helsinki.fi \\ * Correspondence: shella.gilbert-girard@helsinki.fi
}

Received: 7 April 2020; Accepted: 22 April 2020; Published: 25 April 2020

\begin{abstract}
In recent years, bacterial infections have become a main concern following the spread of antimicrobial resistance. In addition, bacterial biofilms are known for their high tolerance to antimicrobials and they are regarded as a main cause of recalcitrant infections in humans. Many efforts have been deployed in order to find new antibacterial therapeutic options and the high-throughput screening (HTS) of large libraries of compounds is one of the utilized strategies. However, HTS efforts for anti-biofilm discovery remain uncommon. Here, we miniaturized a 96-well plate (96WP) screening platform, into a 384-well plate (384WP) format, based on a sequential viability and biomass measurements for the assessment of anti-biofilm activity. During the assay optimization process, different parameters were evaluated while using Staphylococcus aureus and Pseudomonas aeruginosa as the bacterial models. We compared the performance of the optimized 384WP platform to our previously established $96 \mathrm{WP}$-based platform by carrying out a pilot screening of 100 compounds, followed by the screening of a library of 2000 compounds to identify new repurposed anti-biofilm agents. Our results show that the optimized 384WP platform is well-suited for screening purposes, allowing for the rapid screening of a higher number of compounds in a run in a reliable manner.
\end{abstract}

Keywords: bacteria; biofilms; crystal violet; resazurin; screening; Staphylococcus aureus; Pseudomonas aeruginosa

\section{Introduction}

Biofilms are multicellular communities of bacteria that are attached to a surface and embedded in a self-produced polymeric matrix that provide them with protection in various environments, including in the human body. Biofilms are well known for their greater tolerance, not only to the host immune system, but also to antimicrobials; they can withstand 10- to 1000-fold higher concentrations than cells in planktonic form [1-3]. These features make biofilms very difficult to treat and, as a result, they are responsible for the majority of recalcitrant infections, often leading to chronic infections and resulting in a high cost to the healthcare system as well as significant morbidity and mortality [3-6]. Antibiotic treatments can eliminate planktonic cells, but they fail to eradicate biofilms. This has been attributed to a combination of many mechanisms, including the physical protection given by the biofilm matrix, heterogeneity in the metabolic activity of the cells residing within the biofilm, and specific gene expression changes leading to a biofilm-specific phenotype $[3,7,8]$. In many cases, the only possible treatment of a persistent biofilm infection is to surgically remove the biofilm. In the case of 
medical device-related infections, the removal and replacement of the implant is often needed [9]. In addition to a biofilm's intrinsic tolerance to antimicrobials, the development of antibiotic resistance is also a major problem, as increasing amounts of pathogens are multi-resistant to the currently used antibiotics [10,11]. For all of these reasons, finding new therapeutic options that are effective against biofilms is crucial, and intensive research is now ongoing for discovering new antimicrobials [12].

One approach for tackling this challenge is conducting high-throughput screening (HTS) of compound libraries using assays that test the antimicrobial activity of compounds on biofilms grown in 96-well plates (WP) $[13,14]$. This approach is very commonly used in early drug discovery, as it allows the rapid testing of a large number of compounds in a single run, using very small amount of the tested compounds [4,15-17]. The scientific community has extensively used microplates to grow bacterial biofilm [13,18-23], and it has been the preferred sample format used by our group in several studies. For instance, our previous efforts led to the optimization of a phased-screening platform in 96WP, which allowed for monitoring the anti-biofilm activity against Staphylococcus aureus by measuring the viability, biomass, and the biofilm matrix $[14,15,24]$. A primary screening for effects on viable cells and biofilm biomass was conceived, so that two assays could be sequentially performed in a single plate, in order to reduce the time and the amount of materials and compounds required for the analysis. A follow-up assay, involving the fluorescence staining of the poly- $\beta-1,6-N$-acetyl-D-glucosamine (PNAG) component, was further optimized for measuring the specific effects of active compounds on the biofilms matrix of S. aureus [24].

For the initial screening analysis, assays that were based on resazurin and crystal violet staining were first optimized to measure the viability and biofilm biomass of $S$. aureus, respectively. Resazurin is a blue non-fluorescent dye that is only reduced in metabolically active cells into resorufin, a pink fluorescent product that can then be measured. The resazurin staining assay is widely used to evaluate the viability of bacterial cells, as it is fast, shows good repeatability, and has the advantage of discriminating live and dead cells [13]. However, it requires high cell density and living but non-growing cells within biofilms cannot be detected by this method [15]. On the other hand, crystal violet is a widely used basic purple dye that stains negatively charged surfaces (e.g., cell membranes and polysaccharides in the biofilm matrix) [25]. It does not differentiate live from dead cells, but it measures a biofilm's overall biomass, which makes it a useful complementary assay to resazurin staining [24]. Despite the benefits of these staining methods, screening larger libraries using the 96WP-based platform is still labor-intensive and it requires a significant quantity of the tested compounds.

In view of this, we miniaturized both the resazurin and crystal violet assays for microtiter plates with 384 wells (384WP) to test the applicability of this platform to screen larger number of compounds within a same plate in a shorter time and requiring less reagents per well. The optimization was performed with S. aureus ATCC 25,923 and Pseudomonas aeruginosa ATCC 15442, two representative model organisms for gram-positive and gram-negative bacteria, respectively. Parameters, such as the working volume, the concentration of the bacterial inoculum $\left(\mathrm{CFU} \mathrm{mL} \mathrm{m}^{-1}\right)$, as well as the resazurin and crystal violet staining conditions, were optimized. Throughout the optimization process, the screening window coefficient known as the $Z^{\prime}$ factor $\left(Z^{\prime}\right)$, a statistical parameter monitoring the reliability of the screening assay and assay performance, was measured. The signal-to-noise $(\mathrm{S} / \mathrm{N})$ ratio was also monitored. The inhibition of biofilm formation by well-known antibiotics was compared in both 384WP and 96WP to validate the miniaturized model. A proof-of-concept pilot screen of 100 compounds was also performed against $S$. aureus biofilms in both platforms in order to evaluate the correlation of results between $384 \mathrm{WP}$ and $96 \mathrm{WP}$. Based upon these results, a screening campaign against $S$. aureus biofilms was performed while using a library of 2000 structurally diverse compounds, including approved drugs, natural products, as well as biologically relevant compounds that have been reported in peer-reviewed publications. The main goal here was to identify repurposed anti-biofilm compounds because this library was composed by approximately $60 \%$ of FDA-approved or internationally marketed drugs.

Different methods for quantifying the effect of antibacterial compounds have earlier been miniaturized for 384WP, but such efforts have been particularly uncommon for anti-biofilm 
screening. For example, an optical density (OD)-based minimum inhibitory concentration (MIC) assay has been used with $S$. aureus and P. aeruginosa; however, it does not allow for biofilm quantification [26,27]. Redox-based assays, such as those based on resazurin, have been optimized in 384WP format for various bacterial species, including Klebsiella pneumoniae, Helicobacter pylori, Streptococcus pneumoniae, Neisseria species, P. aeruginosa, and S. aureus, but these analyses have only involved planktonic cells [28-32]. A combination of an image-based method and the redox-based 2,3-bis(2-methoxy-4-nitro-5-sulfophenyl)-2H-tetrazolium-5-carboxanilide (XTT) assay to measure the inhibition of P. aeruginosa biofilm formation and dispersion has been developed in 384WP [33]. However, this platform is based on more expensive instrumentation, and it requires the use of a mutant GFP (green fluorescent protein)-tagged bacterial strain, which limits the application of this assay for studying different bacterial strains and species.

By contrast, the 384WP anti-biofilm screening platform that has been miniaturized here involves a cost-friendly combination of sequential staining with resazurin and crystal violet, which can be applied to different bacterial strains and species. For cases where assays conditions that are described here are not directly applicable, all of the optimization steps are described in detail and can be used as guidance. Moreover, both of the assays are fast, easy-to-use and amenable to automation. Thus far, the resazurin assay has been optimized in 384WP for anti-biofilm activity assessment on fungi [34]. In one contribution [35], a combined resazurin and crystal violet-based platform has been used for anti-biofilm screening while using Staphylococcus epidermidis. However, the optimization process was not reported, and a comparative performance study between the 384WP and the conventional 96WP platform was not carried out, either. Our experiments demonstrate that the 384WP format can be successfully used for fluorescence- and absorbance-based anti-biofilm HTS with large compound libraries. As demonstrated here, 384WP provide reliable as well as reproducible screening results that are comparable to the 96WP-based platform. To the best of our knowledge, this is the first validation of a platform combining both resazurin and crystal violet staining assays in 384WP on S. aureus and $P$. aeruginosa. Our optimization efforts were culminated by a screening campaign that involved 2000 compounds, where 77 hits were identified, for a 3.8\% success rate.

\section{Results and Discussion}

\subsection{Optimizing the Working Volume and Initial Bacterial Concentration for 384WP}

When optimizing assays that were aimed at screening a large number of compounds, it is important that these assays are simple to execute, cost-friendly, rapid, and that they require low amounts of materials. These are features shared by both the resazurin and crystal violet staining assays. Since multiple replicates of tested compounds are not typically included, the assays must perform robustly and consistently. To that end, the screening assays must be carefully optimized, and their performance needs to be rigorously monitored, also, throughout screening campaigns, using appropriate screening parameters, such as the screening window coefficient $-Z^{\prime}$, which was originally published by [36].

The screening method was optimized in terms of the assay time and the amount of material needed, and the quality of the method was validated by calculating the $Z^{\prime}$ factor $\left(Z^{\prime}\right)$. We first optimized the bacterial concentration and working volume for the 384WP-based platform. For these initial experiments, the resazurin and crystal violet assays were performed while using the conditions that were previously described by our group [24]. Five starting concentrations of planktonic bacteria, including the cell concentration routinely used in 96WP for S. aureus, were tested. The first of the concentrations was the same as the one used previously in 96WP and the second concentration was proportionally reduced from the first concentration to match the smaller growth area at the bottom of the $384 \mathrm{WP}$ and reach a similar initial concentration per surface $\left(\mathrm{CFU} \mathrm{cm}{ }^{-2}\right)$ concentration. The tested concentrations for S. aureus were $4.00 \times 10^{6} \mathrm{CFU} \mathrm{ml}^{-1}, 7.00 \times 10^{5} \mathrm{CFU} \mathrm{mL}^{-1}, 2.50 \times 10^{6} \mathrm{CFU} \mathrm{mL}^{-1}$, $7.00 \times 10^{4} \mathrm{CFU} \mathrm{mL} \mathrm{m}^{-1}$, and $7.00 \times 10^{3} \mathrm{CFU} \mathrm{mL}^{-1}$. In the case of P. aeruginosa, the following five 
cell concentrations were tested: $1.00 \times 10^{7} \mathrm{CFU} \mathrm{mL}^{-1}, 6.25 \times 10^{6} \mathrm{CFU} \mathrm{mL}^{-1}, 1.75 \times 10^{6} \mathrm{CFU} \mathrm{mL}^{-1}$, $1.75 \times 10^{5} \mathrm{CFU} \mathrm{mL}^{-1}$, and $1.75 \times 10^{4} \mathrm{CFU} \mathrm{mL}^{-1}$.

Each bacterial concentration was tested in 384WP while using two different working volumes (that is, total volume in the wells, $40 \mu \mathrm{L}$ and $50 \mu \mathrm{L}$ ) and two different growth periods ( $18 \mathrm{~h}$ that is routinely used in pre-exposure experiments in 96WP and $42 \mathrm{~h}$ that is used in post-exposure experiments in 96WP). For evaluating the assay performance, the $Z^{\prime}$ factor was calculated and then compared between each condition. The $Z^{\prime}$ evaluates the separation between the maximal signal and the background signal of an assay and it is the most appropriate and widely used statistical parameter to assess the performance of a screening method [36,37]. It ranges between 0 and 1 . A value of 0 signifies no distinction between the maximal and minimal signal, whereas a value of 1 indicates that the signal separation is ideal and infinite (an ideal screening assay). Consequently, a $Z^{\prime}$ value that is close to 0 indicates that the assay does not perform well and it requires more optimization. Generally, a $Z^{\prime}$ value above 0.5 indicates a well-performing assay, although, in the case of cell-based assays, a $Z^{\prime}$ above 0.35 is already considered to be acceptable [38]. The difference between the maximal and minimal signals obtained in each condition was also compared. Parameters that resulted in the best $Z^{\prime}$ factor were selected as being optimal. The correlation between the $Z^{\prime}$ factor and the signal-to-noise ratio $(\mathrm{S} / \mathrm{N})$, as defined by [36], obtained for both assays, during the optimization stage, was also monitored (Supplementary Figure S1a). The two statistical parameters showed a consistent correlation, where a good $Z^{\prime}$ value (above 0.5 ) generally equaled an $\mathrm{S} / \mathrm{N}$ above six.

When testing the platform with $S$. aureus using both the resazurin and crystal violet on $18 \mathrm{~h}$-old or $42 \mathrm{~h}$-old biofilms (Figure 1), the two different working volumes (40 and $50 \mu \mathrm{L}$ ) did not significantly affect the $Z^{\prime}$ values $(p \geq 0.05)$ or the maximum minus the minimum signals. With a working volume as low as $40 \mu \mathrm{L}$, it was possible to obtain high quality data and this working volume was therefore selected for further experiments. A lower working volume $(25 \mu \mathrm{L})$ was also tested, but the wells fully dried out during incubation, so we concluded that so small working volumes in $384 \mathrm{WP}$ assays involving longer incubation times would not be feasible due to evaporation issues. The initial S. aureus concentration did not significantly impact the $Z^{\prime}$ values regarding the resazurin assay; the majority of the tested S. aureus concentrations reached a biofilm state with similar metabolic activity after 18 or $42 \mathrm{~h}$ of incubation. The $7.00 \times 10^{4} \mathrm{CFU} \mathrm{mL}{ }^{-1}$ was the lowest cell concentration, resulting in a good $\mathrm{Z}^{\prime}$ value $(\geq 0.5)$ for both the young $(18 \mathrm{~h})$ and more mature $(42 \mathrm{~h})$ biofilms. A slightly increased difference between the maximal and minimal signals was observed with increased S. aureus concentrations, even though it did not translate into a higher $Z^{\prime}$ value.

The crystal violet assay was more influenced by the initial $S$. aureus concentrations, and a lower cell concentration was usually related to a lower $Z^{\prime}$ value and a smaller difference between the maximum and minimum signals. This staining method generally resulted in a lower performance than resazurin; it requires more steps that can introduce variability and is more laborious, which translates into a lower reproducibility and a poorer dynamic range [39]. For this assay, all of the cell concentrations from $2.50 \times 10^{6} \mathrm{CFU} \mathrm{mL} \mathrm{m}^{-1}$ and higher still resulted in a good $\mathrm{Z}^{\prime}$ value $(\geq 0.5)$. As our findings indicated that the resazurin staining produces more reliable results than the crystal violet staining, and since both assays are performed sequentially in the same plate, the initial bacterial concentration that was selected for the subsequent assays was the compromise of both staining methods $\left(7.00 \times 10^{4} \mathrm{CFU} \mathrm{mL}^{-1}\right)$, which performed well with the resazurin staining while still giving an acceptable performance with crystal violet. 
$\underline{\text { Resazurin }}$

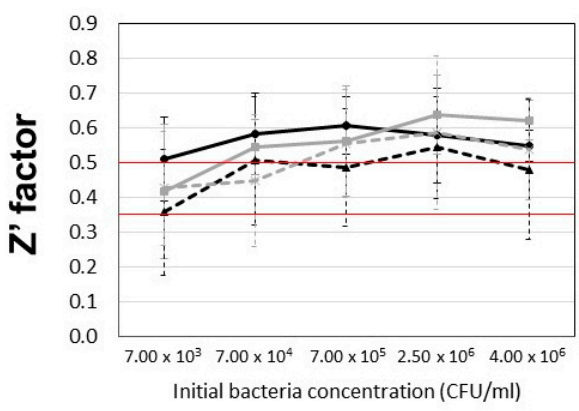

(a)

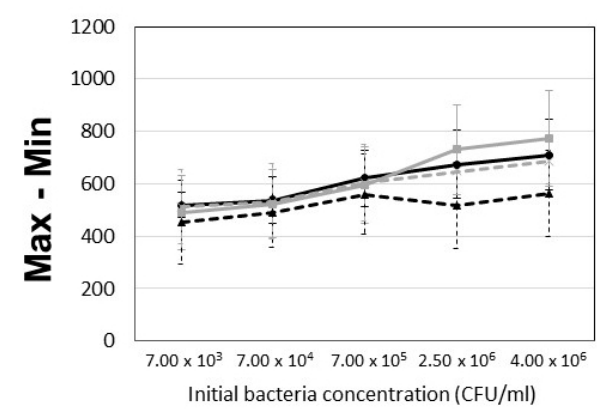

(c)

\section{Crystal violet}

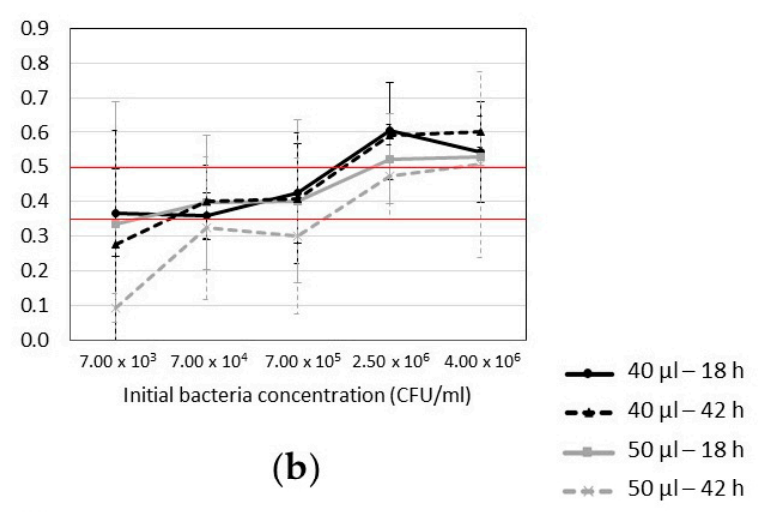

(d)

Figure 1. Effect of different initial S. aureus concentrations and working volumes on the performance of a miniaturized biofilm screening assay in 384WP. Assay performance is measured using the $\mathrm{Z}^{\prime}$ factor $(\mathbf{a}, \mathbf{b})$ and the maximum minus minimum signal $(\mathbf{c}, \mathbf{d})$ of the resazurin and crystal violet staining of S. aureus biofilms grown for $18 \mathrm{~h}$ or $42 \mathrm{~h}$ in a volume of $40 \mu \mathrm{L}$ or $50 \mu \mathrm{L}$ with different initial bacterial concentration in 384WP. Maximum minus minimum results are expressed in relative fluorescence units (RFUs) for resazurin or relative absorbance units (RAUs) for crystal violet. The results are based on 2-4 independent biological replica experiments, each plate containing 28-40 technical replicates for each condition and 30 media control replicates. The red lines in panels a and $b$ represent the thresholds for determination of the quality of the assay: acceptable $(Z=0.35)$ and $\operatorname{good}(Z=0.5)$.

The optimized screening platform was also tested with gram-negative P. aeruginosa biofilms (Figure 2). With this strain, neither the volume nor the initial bacterial concentration affected the $Z^{\prime}$ values for both staining assays $(p \geq 0.05)$. The resazurin assay signals varied significantly, but the position of the biofilm controls (maximal signal) within the plate affected more strongly the metabolic activity of the biofilms than the initial quantity of bacteria. Wells on the edges of the plate showed more varying results, which was also found between different replica plates. While this effect is well known in 96WP, it was particularly noticeable in $384 \mathrm{WP}$, probably because of the smaller size of the wells and smaller working volumes. The resazurin assay did not perform as well with P. aeruginosa as it did with $S$. aureus and it rarely resulted in $Z^{\prime}$ values above 0.35 , indicating the need for optimizing other assay parameters or more accurate optimization of the tested parameters for this gram-negative model. As the conditions for this assay were not fully optimized, these observations were considered to be normal at this point. The crystal violet staining results did not vary much with respect to the working volume or the initial cell concentration. For further experiments, a bacterial concentration of $1.75 \times 10^{5} \mathrm{CFU} \mathrm{mL}{ }^{-1}$ was selected, as it resulted in lower intra-plate variability when using resazurin as the staining method. For the next part of the optimization, different parameters of the resazurin and crystal violet staining methods were adjusted in order to select the best conditions for both bacterial species. 


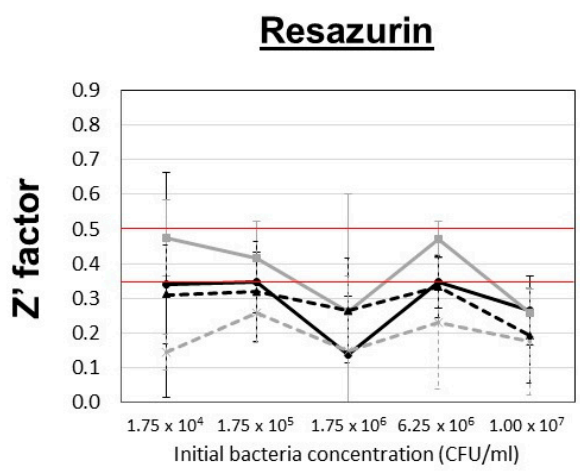

(a)

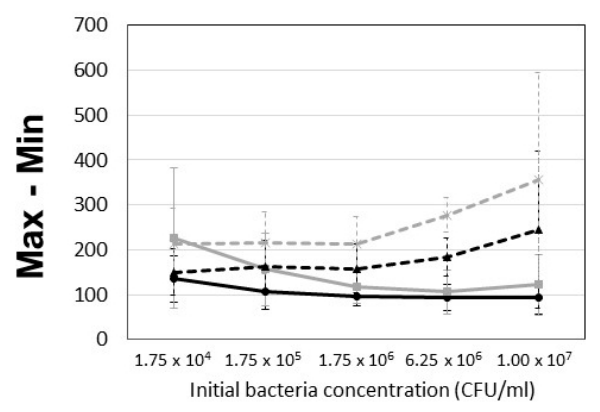

(c)

\section{Crystal violet}

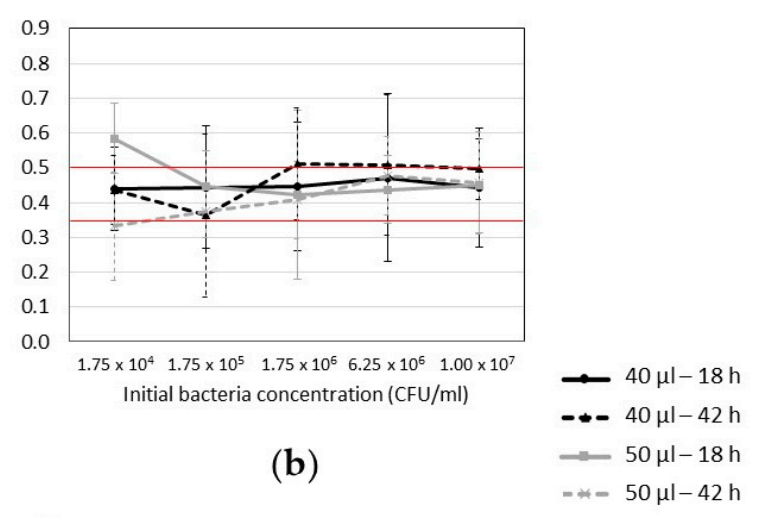

(d)

Figure 2. The effect of different initial P. aeruginosa concentrations and working volumes on the performance of a miniaturized biofilm screening assay in 384WP. Assay performance is measured using the $Z^{\prime}$ factor $(\mathbf{a}, \mathbf{b})$ and the maximum minus minimum signal $(\mathbf{c}, \mathbf{d})$ of the resazurin and crystal violet staining of P. aeruginosa biofilms grown for $18 \mathrm{~h}$ or $42 \mathrm{~h}$ in a volume of $40 \mu \mathrm{L}$ or $50 \mu \mathrm{L}$ with different initial bacterial concentration in 384WP. Maximum minus minimum results are expressed in RFUs for resazurin or RAUs for crystal violet. Results are based on 3-4 independent biological replica experiments, each plate containing 28-40 technical replicates for each condition and 30 media control replicates. The red lines in panels $\mathrm{a}$ and $\mathrm{b}$ represent the thresholds for the determination of the quality of the assay: acceptable $(Z=0.35)$ and good $(Z=0.5)$.

\subsection{Optimizing the Conditions for Resazurin Staining}

Our pre-existing screening platform developed in-house [24] is based on staining the biofilms first with resazurin and then by crystal violet in the same 96WP. Using both assays has the advantage of giving more information of the activity of an antibacterial compound and its mechanism of action (MoA) and doing it in a single plate allows for correlating the results of each assay to a single biofilm. When evaluating the anti-biofilm potential of a compound, it is important to make a distinction between the compounds that eliminate living cells (i.e., prevent resazurin reduction), and those that prevent biofilm formation/disrupt the biofilm (i.e., reduce crystal violet staining). Analyzing the effects of the compounds on biofilms using both staining methods is of particular importance, because, if only living cells are eliminated, the remaining biofilm matrix becomes an ideal environment for a quick recolonization, leading to a recurrence of the infection $[18,40]$. The non-invasive nature of resazurin $[24,41]$ allows for the subsequent performance of additional staining assays within the same plate, which minimizes the plate-to-plate variations when using multiple staining methods during the screening process. The correlation between the $\mathrm{Z}^{\prime}$ factor and the $\mathrm{S} / \mathrm{N}$ obtained for the optimization of the conditions of both the resazurin and crystal violet assays was monitored (Supplementary Material Figure S1b). Similar to the optimization of working volume and bacteria concentration, there was a clear correlation between the $Z^{\prime}$ and the $S / N$ and a good $Z^{\prime}$ value (above 0.5 ) translated into an $S / N$ above 6 . 
The resazurin assay measures the metabolic activity of the cells, which can greatly vary between different strains, indicating that the method has to be optimized for each tested species or strain $[24,42]$. Here, the resazurin staining conditions were optimized using $40 \mu \mathrm{L}$ as the working volume with an initial cell concentration of $7.00 \times 10^{4} \mathrm{CFU} \mathrm{mL} \mathrm{mL}^{-1}$ for S. aureus and $1.75 \times 10^{5} \mathrm{CFU} \mathrm{mL} \mathrm{m}^{-1}$ for P. aeruginosa. Different resazurin concentrations within the range of $20 \mu \mathrm{M}$ to $200 \mu \mathrm{M}$ were tested and fluorescence was measured at different time points (from 5 to $80 \mathrm{~min}$.).

With the $S$. aureus $18 \mathrm{~h}$-old biofilms, the $\mathrm{Z}^{\prime}$ values that were obtained while testing the various concentrations of resazurin $(20-100 \mu \mathrm{M})$ were consistently above 0.35 after $10 \mathrm{~min}$. of incubation and above 0.5 after $30 \mathrm{~min}$. (Figure $3 \mathrm{a}$ ). With resazurin at $20 \mu \mathrm{M}$, a concentration routinely used in 96WP, the assay performance was overall better when compared to higher resazurin concentrations. In addition, only a minimum of $10 \mathrm{~min}$. of incubation was needed to reach a $\mathrm{Z}^{\prime}$ above 0.5 . With $42 \mathrm{~h}$-old biofilms, resazurin at $40 \mu \mathrm{M}$ was slightly more optimal and an incubation of at least $30 \mathrm{~min}$. was required to reach a $Z^{\prime}$ above 0.5 (Figure 3b), but only a marginal benefit was obtained with a longer incubation time. In general, the longer the incubation was, the better the $Z^{\prime}$ factor and the wider the separation between the maximum and minimum signals (Figure $3 c, d$ ). On the other hand, while the difference between the maximum and minimum signals significantly increased over time, the increase of the $Z^{\prime}$ factor slowed down quickly. Therefore, for further experiments, resazurin at the concentration of $20 \mu \mathrm{M}$ was selected to test $18 \mathrm{~h}$-old S. aureus biofilms and $40 \mu \mathrm{M}$ for $42 \mathrm{~h}$-old biofilms using $30 \mathrm{~min}$. incubation for each.

As expected, different conditions were required for the staining of P. aeruginosa, thus confirming the need for species-dependent optimization (Figure 4). With both $18 \mathrm{~h}$-old or $42 \mathrm{~h}$-old biofilms, regardless of the concentration of resazurin used, a $Z^{\prime}$ above 0.5 could never be reached and only the longest incubation times would allow for reaching a $Z^{\prime}$ of at least 0.3. Despite the higher initial cell concentration used, $P$. aeruginosa produced a much lower fluorescence signal than $S$. aureus. The possible explanations include strain-specific differences affecting the reduction rate of resazurin or a greater thickness or sliminess of $P$. aeruginosa biofilms hampering the penetration of resazurin [42]. Therefore, P. aeruginosa biofilms were stained at $37^{\circ} \mathrm{C}$, which significantly increased the $Z^{\prime}$ factor, in order to increase the metabolic activity and improve the sensitivity of the resazurin assay. With long incubation times (60-80 min.), all of the tested resazurin concentrations provided acceptable ( $\left.Z^{\prime}>0.35\right)$ to good $\left(Z^{\prime}>0.5\right)$ performance values with 18 h-old P. aeruginosa biofilms (Figure 4a). The resazurin concentration of $100 \mu \mathrm{M}$ resulted in the best $\mathrm{Z}^{\prime}$ factor with both the $18 \mathrm{~h}$ and $42 \mathrm{~h}$-old biofilms (Figure $4 \mathrm{a}, \mathrm{c}$ ). An incubation of at least $60 \mathrm{~min}$. with $18 \mathrm{~h}$-old biofilms and $80 \mathrm{~min}$. with $42 \mathrm{~h}$-old biofilms was necessary to ensure proper assay performance. Of note, performing the assay at $37^{\circ} \mathrm{C}$ also increases the fluorescence signal obtained from the S. aureus biofilms, but further resazurin staining assays with S. aureus were still performed at RT, as carrying out the assay at RT was enough to obtain good assay performance. 


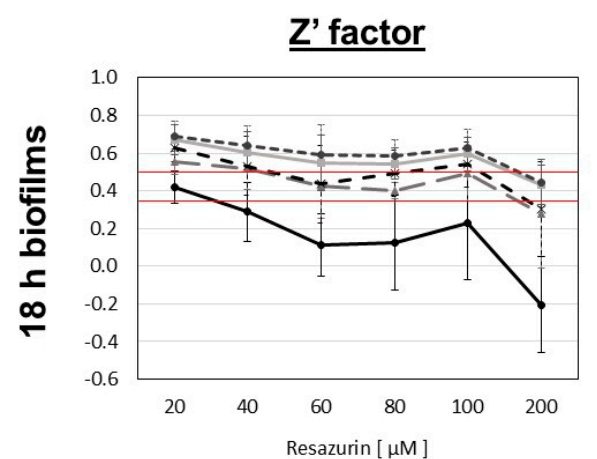

(a)

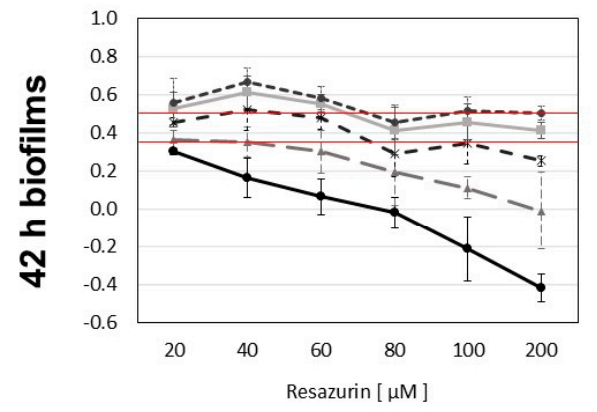

(c)

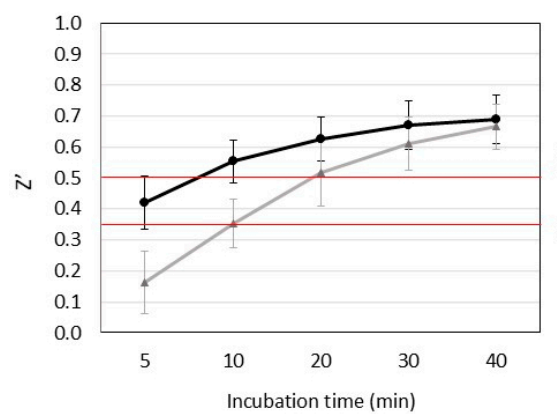

(e) $\underline{\text { Max - Min }}$

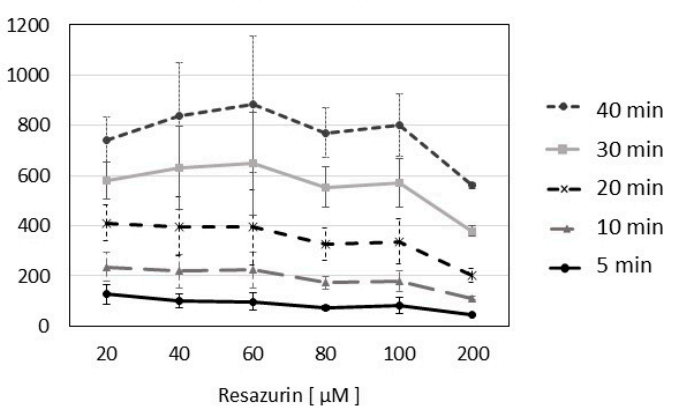

(b)

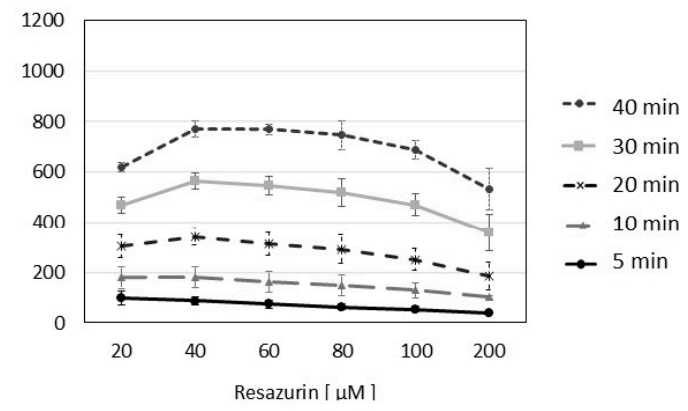

(d)

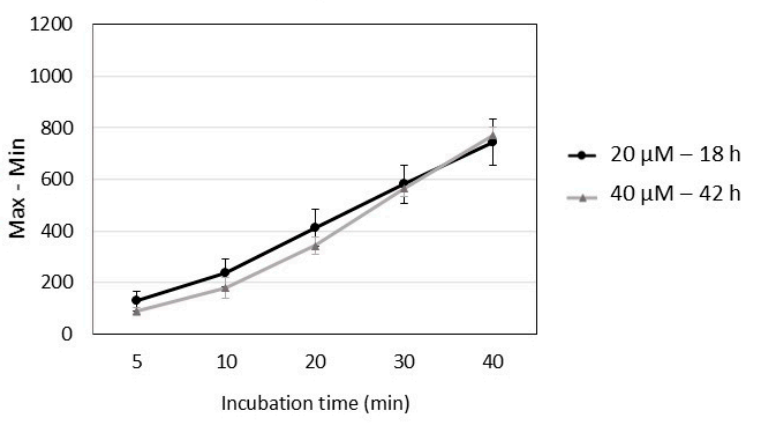

(f)

Figure 3. Effect of different resazurin concentrations and incubation times with the dye on the performance of a miniaturized biofilm screening assay in $384 \mathrm{WP}$ with S. aureus. Assay performance is measured using $Z^{\prime}$ factor $(\mathbf{a}, \mathbf{c})$ and maximum minus minimum signal $(\mathbf{b}, \mathbf{d})$ of the resazurin staining of $S$. aureus biofilms grown for $18 \mathrm{~h}$ or $42 \mathrm{~h}$ in a volume of $40 \mu \mathrm{L}$ with a concentration of the bacterial inoculum of $7.00 \times 10^{4}(\mathrm{CFU}) \mathrm{mL}^{-1}$. (e,f) show the $\mathrm{Z}^{\prime}$ factor and the maximum minus minimum signal obtained with the best resazurin concentration over time. Maximum minus minimum results are expressed in RFUs. Results are based on 2-4 independent biological replica experiments performed at room temperature (RT), each plate containing from 12 to 42 technical replicates and 16 media control replicates for each condition. The red lines in panels $\mathrm{a}, \mathrm{c}$ and e represent the thresholds for determination of the quality of the assay: acceptable $\left(Z^{\prime}=0.35\right)$ and $\operatorname{good}\left(Z^{\prime}=0.5\right)$. 
$\underline{\text { Z' factor }}$

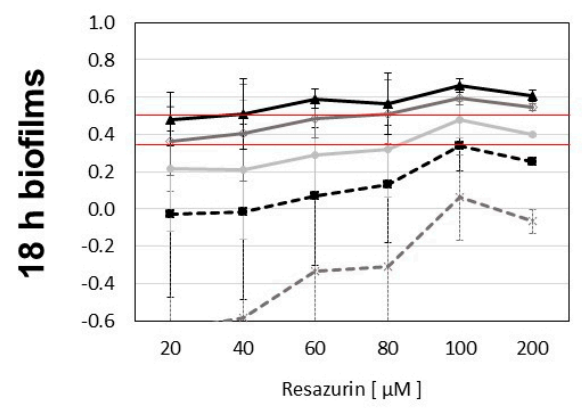

(a)

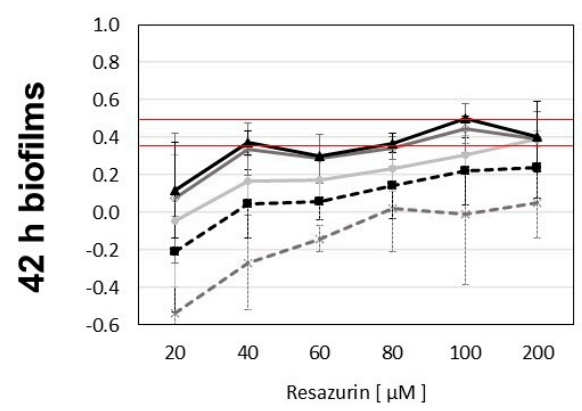

(c)

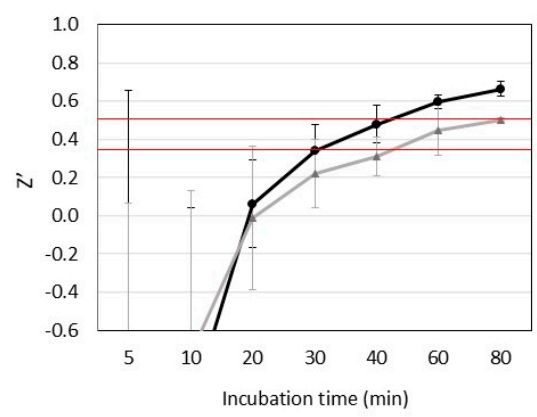

(e) $\underline{\text { Max - Min }}$

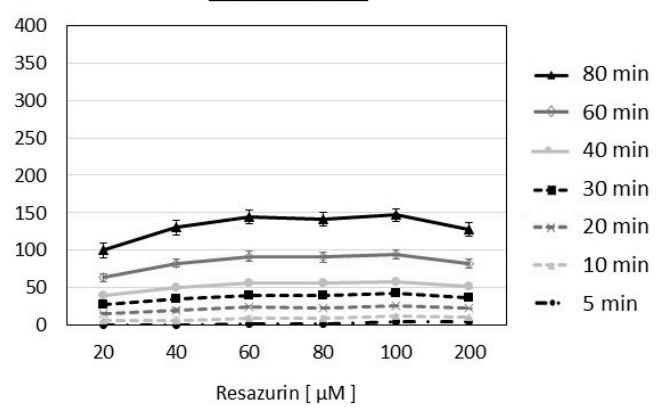

(b)

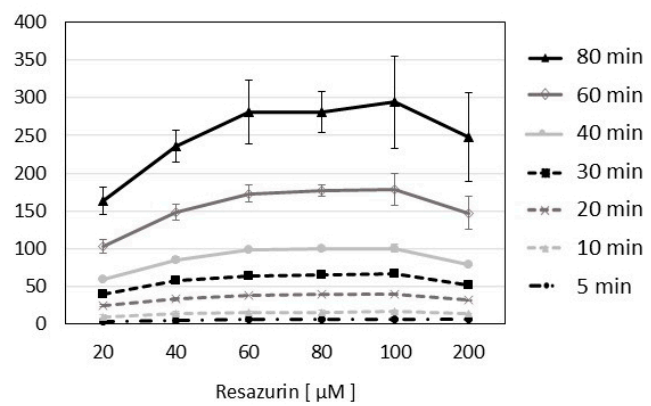

(d)

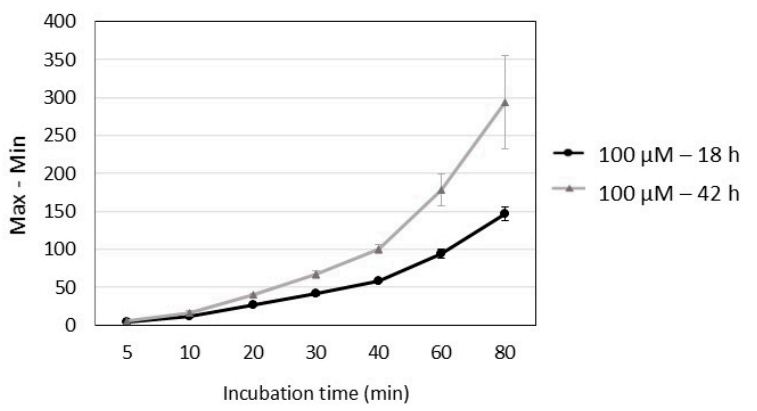

(f)

Figure 4. Effect of different resazurin concentrations and incubation times with the dye on the performance of a miniaturized biofilm screening assay in 384WP with P. aeruginosa. Assay performance is measured using $Z^{\prime}$ factor $(\mathbf{a}, \mathbf{c})$ and maximum minus minimum signal $(\mathbf{b}, \mathbf{d})$ of the resazurin staining of $P$. aeruginosa biofilms grown for $18 \mathrm{~h}$ or $42 \mathrm{~h}$ in a volume of $40 \mu \mathrm{L}$ with a concentration of the bacterial inoculum of $1.75 \times 10^{5} \mathrm{CFU} \mathrm{mL}{ }^{-1}$. (e,f) show the $\mathrm{Z}^{\prime}$ factor and the maximum minus minimum signal obtained with the best resazurin concentration over time. Maximum minus minimum results are expressed in RFUs. Results are based on 2 independent biological replica experiments performed at $37^{\circ} \mathrm{C}$, each plate containing from 36 to 48 technical replicates and 12 media control replicates for each condition. The red lines in panels a, c, and e represent the thresholds for determination of the quality of the assay: acceptable $\left(Z^{\prime}=0.35\right)$ and $\operatorname{good}\left(Z^{\prime}=5\right)$.

\subsection{Optimizing the Conditions for Crystal Violet Staining}

The crystal violet staining was performed on the same biofilms that were used for the resazurin staining. Different concentrations of crystal violet and lengths of incubation times were tested with both bacterial species. In the case of $S$. aureus, the absorbance of the stained biomass was also measured at different time points after the addition of ethanol to dissolve the bound crystal violet. The $Z^{\prime}$ factor increased proportionally to the dissolution time for one hour and then stabilized (Supplementary Figure S2b). An hour was consequently selected as the most optimal dissolution time for the bound crystal violet. Additionally, different incubation times with the dye (5, 10, and $15 \mathrm{~min}$.) 
did not significantly affect the assay performance (Supplementary Figure S2a); therefore, the shortest time ( $5 \mathrm{~min}$.) was selected for further assays. While the crystal violet assay more variable results than resazurin [42], statistically acceptable results could still be obtained in our study.

With S. aureus biofilms (Figure $5 \mathrm{a}, \mathrm{c}$ ) the crystal violet at $0.023 \%(v / v)$ provided higher $Z^{\prime}$ values, although the difference between the maximum and minimum signal was greater with higher crystal violet concentrations. The most likely reason for this could be the reduced inter-well variability detected with lower crystal violet concentrations, since using higher concentrations of crystal violet occasionally led to darkly stained media control wells containing no bacteria. With P. aeruginosa (Figure 5b,d), the three lowest concentrations of crystal violet resulted in very similar $Z^{\prime}$ factors and maximum minus minimum values, especially on $42 \mathrm{~h}$-old biofilms. The crystal violet concentration of $0.1 \%(v / v)$ gave an average $Z^{\prime}$ value above 0.5 with both young and older P. aeruginosa biofilms.

$\underline{\text { S. aureus }}$

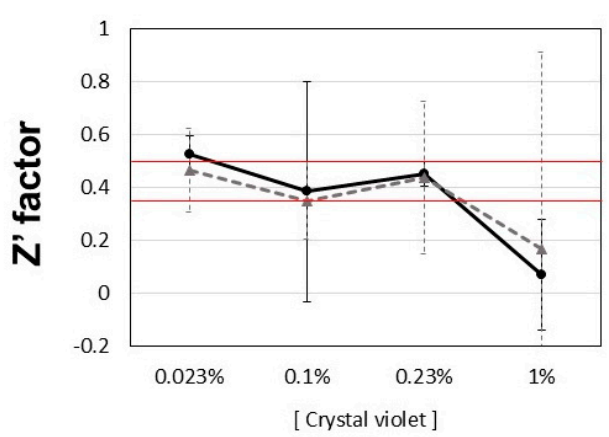

(a)

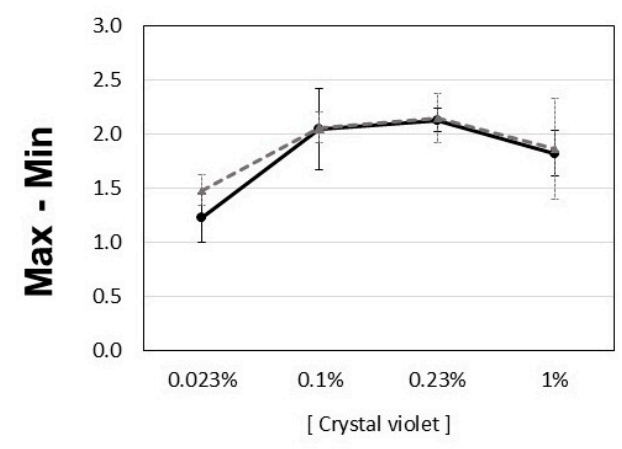

(c)

\section{$\underline{\text { P. aeruginosa }}$}

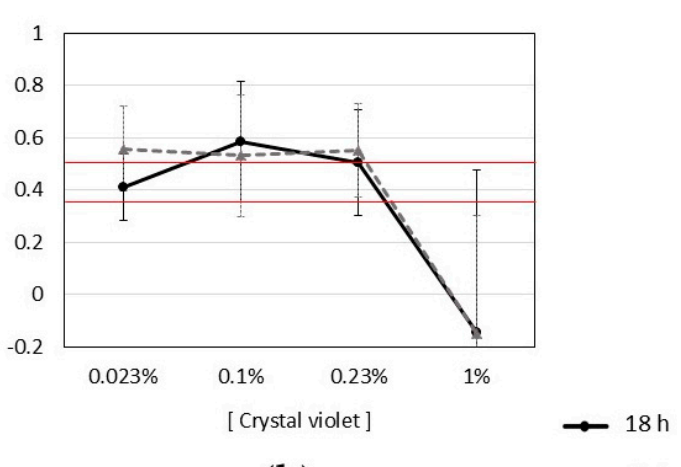

(b)

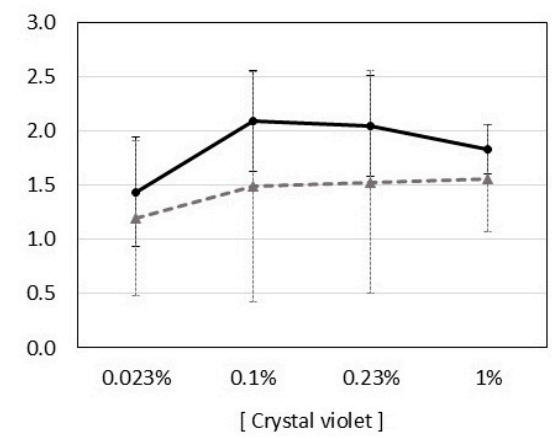

(d)

Figure 5. Effect of different crystal violet concentrations on the performance of a miniaturized biofilm screening assay in $384 \mathrm{WP}$. Assay performance is measured using $\mathrm{Z}^{\prime}$ factor $(\mathbf{a}, \mathbf{b})$ and maximum minus minimum signal $(\mathbf{c}, \mathbf{d})$ of the crystal violet staining of S. aureus and P. aeruginosa biofilms grown for $18 \mathrm{~h}$ or $42 \mathrm{~h}$ in a volume of $40 \mu \mathrm{L}$ with a concentration of the bacterial inoculum of $7.00 \times 10^{4} \mathrm{CFU} \mathrm{mL}^{-1}$ (S. aureus) or $1.75 \times 10^{5} \mathrm{CFU} \mathrm{mL}^{-1}$ (P. aeruginosa). Maximum minus minimum results are expressed in RAUs. Results are based on 3-5 independent biological replica experiments, with each plate containing from eight (one experiment) to 96 technical replicates and 12 to 32 media control replicates for each condition. The red lines in panels a and $b$ represent the thresholds for determination of the quality of the assay: acceptable $(Z=0.35)$ and $\operatorname{good}(Z=5)$.

\subsection{Biofilm Formation in 384WP in Comparison with 96WP}

Next, we compared the number of viable cells attached as biofilms in 384WP versus 96WP. The S. aureus and P. aeruginosa biofilms that were produced in each plate were scraped, serially diluted, and plated on tryptic soy agar (TSA). Viable colonies (CFUs) were counted the next day and the amount of CFUs in each biofilm was normalized to the area $\left(\mathrm{cm}^{2}\right)$ of the wells in both systems (Figure 6). With S. aureus, a similar amount of $\mathrm{CFU} \mathrm{\textrm {cm } ^ { - 2 }}$ was observed between the $18 \mathrm{~h}$-old and $42 \mathrm{~h}$-old 
biofilms, as well as in the 96WP and 384WP plates, suggesting a similar cell density. On the other hand, with P. aeruginosa, the number of CFU cm${ }^{-2}$ was slightly reduced by $0.6-0.8 \log$ in $384 \mathrm{WP}$ when compared to 96WP. It could be that biofilms that formed by P. aeruginosa were less dense or had a different structure in the smaller wells of $384 \mathrm{WP}$, which stimulated cell dispersal. However, overall, a relatively similar cell density was still achieved in biofilms that were grown for $18 \mathrm{~h}$ and $42 \mathrm{~h}$ in each plate model. It is possible that, in the restricted space of the wells, biofilms reached a maximal number of cells within the given area or that the time span between the two time points studied was not long enough to result in a detectable cell density difference. In any case, the differences between responses in $18 \mathrm{~h}$ versus $42 \mathrm{~h}$ biofilms cannot be attributed to a larger number of viable cells attached on the wells, at least on our assay conditions.

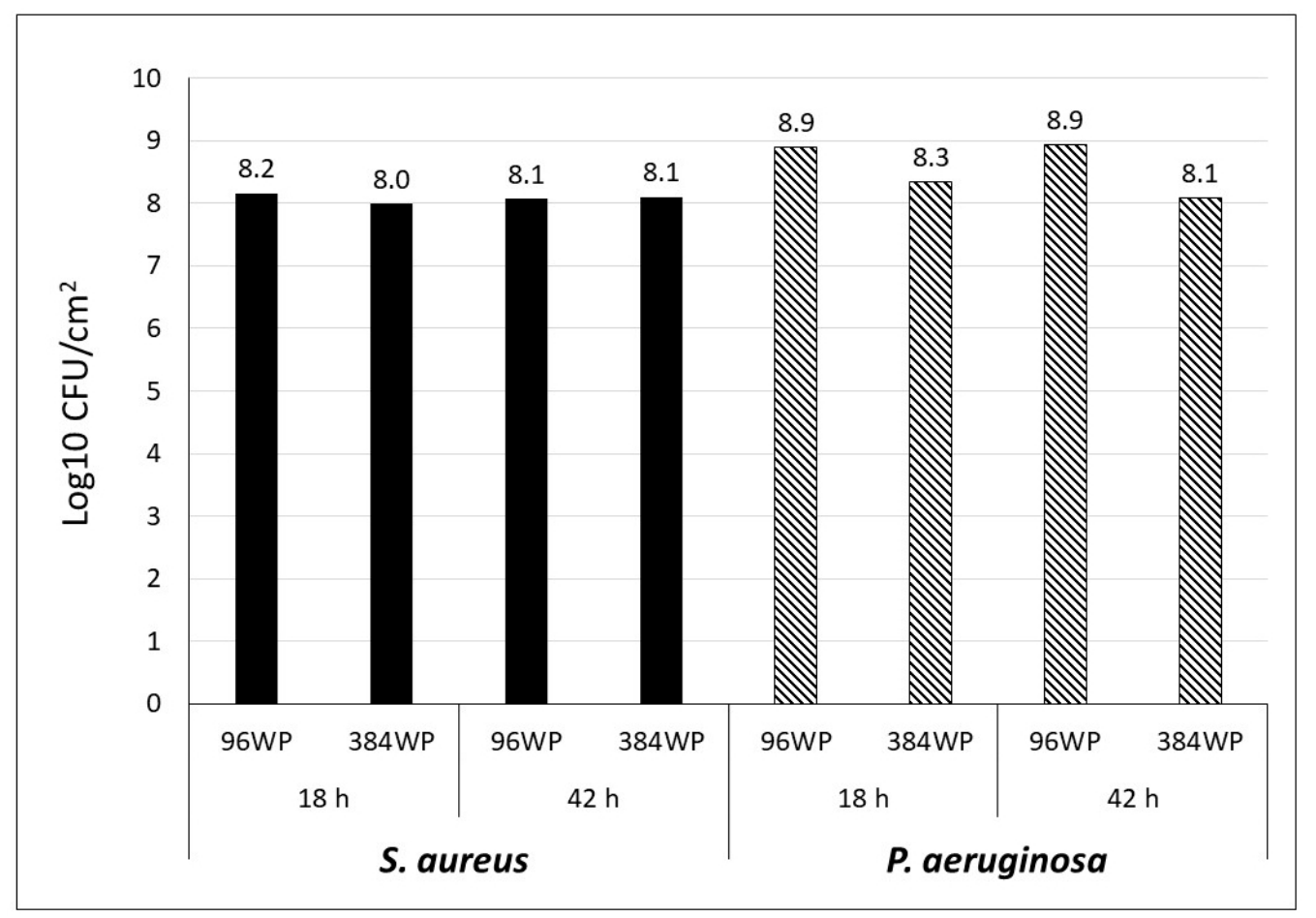

Figure 6. Log10 of the CFUs per $\mathrm{cm}^{2}$ of S. aureus (black) and P. aeruginosa (striped) biofilms grown in 96WP or $384 \mathrm{WP}$ for $18 \mathrm{~h}$ or $42 \mathrm{~h}$. The data represents the average of 16-22 biofilms (technical replicates) from $2-5$ independent biological replica experiments.

\subsection{Susceptibility of S. aureus Biofilms Formed in 384WP and 96WP to Antibiotics}

We further evaluated the susceptibility of S. aureus biofilms to a panel of standard antibiotics at seven different concentrations ( $10 \mu \mathrm{M}$ to $0.01 \mathrm{pM})$ while using the pre- and post-exposure modes in order to compare the screening results obtained between the miniaturized 384WP platform and the characterized 96WP platform (Figure 7). Overall, the susceptibility of the biofilms was comparable in both models, which confirms the applicability of the 384WP model for antibacterial activity assessment. The biofilm viability inhibition percentages that were obtained with the resazurin assay in the pre-exposure mode were very similar between the 96WP and the $384 \mathrm{WP}$, with an average difference of inhibition percentage under $6 \%(5.5 \% \pm 5.8 \%)$. When using the post-exposure mode, the difference between the viability inhibition results that were obtained in 96WP and in 384WP increased, with an average difference of inhibition of almost $15 \%(14.3 \% \pm 7.7 \%)$. With the crystal violet assay, an average difference of biomass formation inhibition of $11.4 \% \pm 8.9 \%$ was observed between 96WP and 384WP in pre-exposure and $10.6 \% \pm 7.5 \%$ in post-exposure. Thus, performing the assays in $384 \mathrm{WP}$ rather than in 96WP produced a very similar outcome and did not result in generally higher or lower inhibition values at the different concentrations of antibiotics tested. Still, it is important to 
note that, in our experiments, with both species, the initial bacterial concentration was about 70 times lower in 384WP than in 96WP, which could have affected the antimicrobial susceptibility during the early stages of bacterial growth prior to biofilm formation and especially in pre-exposure experiments. Some compounds that have a rapid MoA on bacteria might perform differently in both models when using the same assay conditions that are described here.

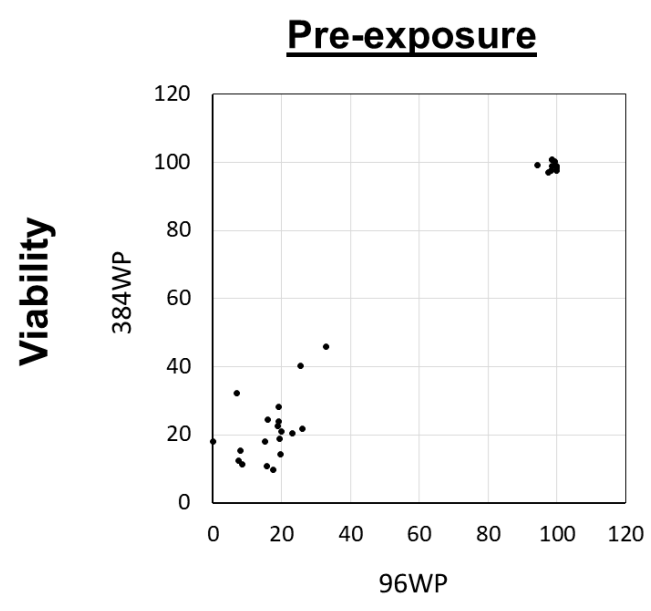

(a)

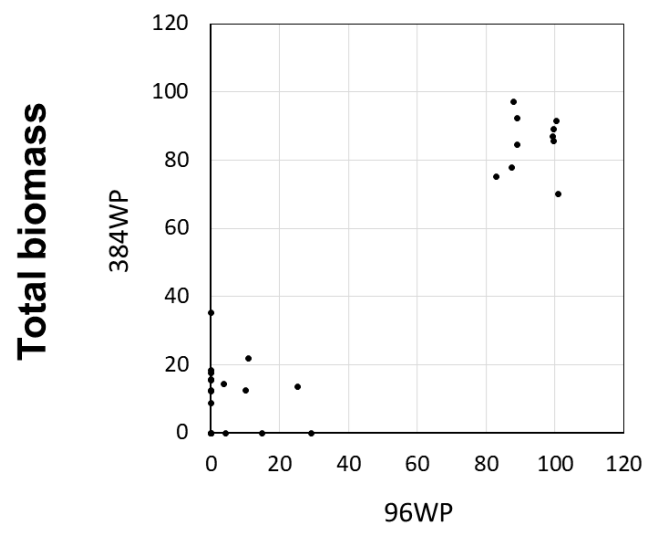

(c)

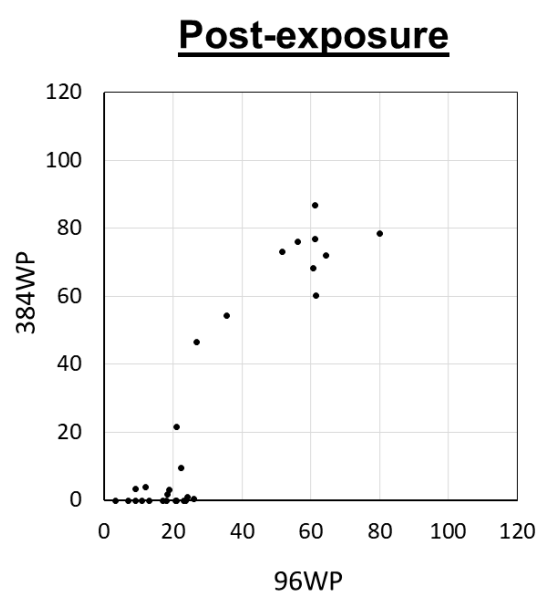

(b)

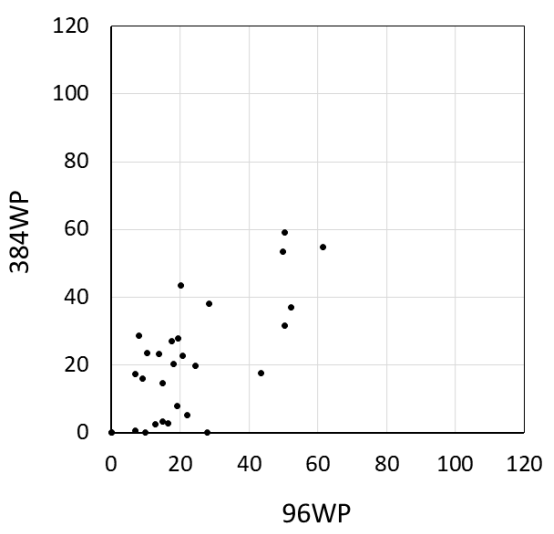

(d)

Figure 7. Correlation of the susceptibility of $S$. aureus biofilms to different concentrations of four antibiotics (rifampicin, oxacillin, doxycycline, penicillin G) in 96WP and 384WP in pre- (a,c) and post-exposure $(\mathbf{b}, \mathbf{d})$ modes. The effect of the antibiotics on the biofilms was assessed by resazurin ("Viability", (a,b)) and crystal violet ("Total Biomass", (c,d)) staining. Results are expressed as inhibition percentages of viability or biomass in comparison to untreated biofilms and they are based on two independent biological replica experiments, with two (96WP) or eight (384WP) technical replicates for each condition.

\subsection{Antibacterial Pilot Screening Against S. aureus Biofilms in 384WP and 96WP Platforms}

We performed a pilot screen of 100 compounds, which included natural derivatives as well as 10 antibiotics, at $10 \mu \mathrm{M}$, to further verify the applicability of $384 \mathrm{WP}$ for antibacterial screening in a larger scale (Figure 8). The list of all of the tested compounds, sources, and their screening results in 96WP and 384WP is available in the Supplementary Materials (Table S1). Similar to previous findings, the majority of the results correlated between $384 \mathrm{WP}$ and 96WP, but a slight difference was observed; the inhibition values that were obtained using post-exposure mode in $384 \mathrm{WP}$ were generally higher than values obtained in $96 \mathrm{WP}$ (by $18 \%$ with resazurin and $11 \%$ with crystal violet). This difference was not observed with the pre-exposure mode and it would be unlikely to cause major differences 
in the conclusions of a screening, since screenings in the early discovery of antibacterial compounds typically evaluate the prevention of growth (pre-exposure) rather than the antimicrobial effects on pre-existing biofilms (post-exposure). It is still a difference that must be taken in consideration for post-exposure screenings.

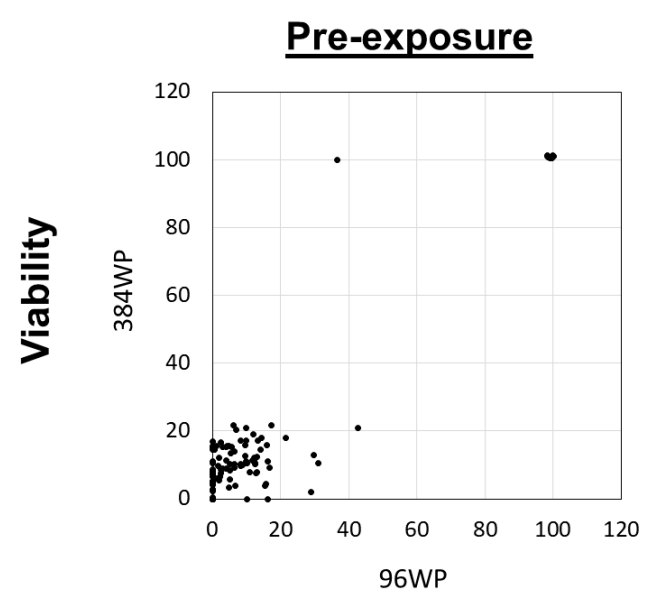

(a)

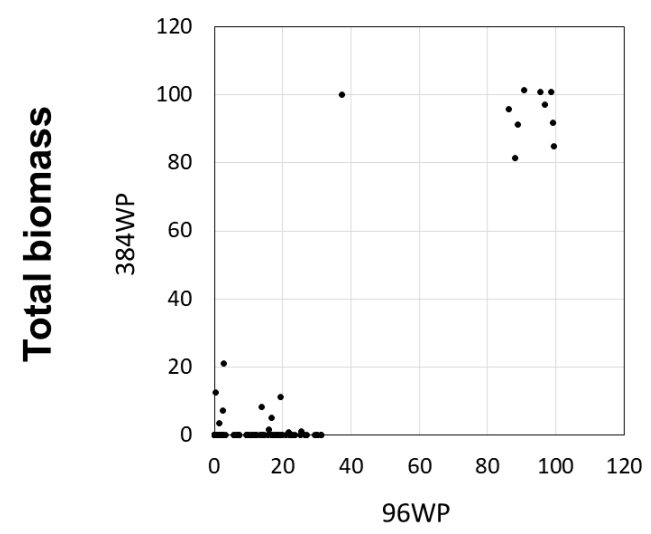

(c)

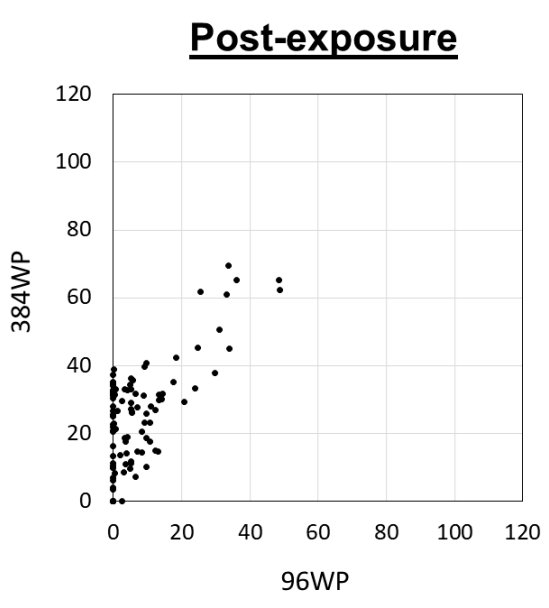

(b)

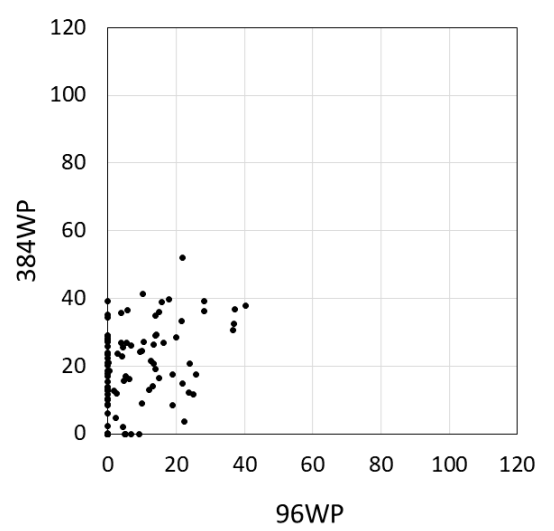

(d)

Figure 8. Inhibition of $S$. aureus biofilms by 100 compounds tested at $10 \mu \mathrm{M}$ in $96 \mathrm{WP}$ and $384 \mathrm{WP}$ in pre $(\mathbf{a}, \mathbf{c})$ and post-exposure $(\mathbf{b}, \mathbf{d})$ modes. The effect of the compounds on the biofilms was assessed by resazurin ("Viability, (a,b)) and crystal violet ("Total biomass", (c,d)) staining. Results are expressed as inhibition percentages of viability or biomass in comparison to untreated biofilms and they are based on two independent biological replica experiments, with one (96WP) or two (384WP) technical replicates for each condition.

In the pre-exposure mode, one of the antibiotics (streptomycin) resulted in significantly different inhibition values in 384WP and 96WP. An inhibition of $100 \%$ with streptomycin was observed in 384WP, while this antibiotic only inhibited 30 to $40 \%$ of the biofilm formation in 96WP. Such a phenomenon was exclusively seen with streptomycin. It is plausible that the lower concentration of the bacterial cells in $384 \mathrm{WP}$ in the beginning of the experiment affected the outcome of the assay. However, this difference between 384WP and 96WP was not observed when using the post-exposure mode for this antibiotic. This can be explained by the fact that, after $18 \mathrm{~h}$ (when the treatment with streptomycin starts in the post-exposure assay), the number of viable cells attached is very similar between 384WP and 96WP (Figure 6), making comparable effects of streptomycin in both systems. Overall, the average difference in the resazurin and crystal violet staining results between 384WP and 96WP for the same compounds was $8.7 \% \pm 9.3 \%$ in pre-exposure and $15.6 \% \pm 10.5 \%$ in post-exposure. Therefore, the results that 
were obtained in both plates were quite similar for the indicated compounds. Of note, the variations between replicates were slightly higher in $384 \mathrm{WP}$, with an average SD that was approximately $4 \%$ higher in 384WP than in 96WP. Taken together, we conclude that the optimized platform performed in $384 \mathrm{WP}$ is as reliable as the 96WP-based model and it can be used to screen novel anti-biofilms.

\subsection{Screening Campaign Against S. aureus Biofilms in 384WP}

The optimized 384WP platform was next used to screen a library containing 2000 compounds against $S$. aureus biofilms, both for the capacity to prevent biofilm formation (pre-exposure mode) and to destroy pre-formed biofilms (post-exposure mode) (Figure 9). As in the pilot screen, the compounds were tested at $10 \mu \mathrm{M}$ and biofilms were grown and analyzed, as described above. We set-up empiric thresholds to categorize the screening results. Compounds displaying an inhibition of at least $80 \%$ were regarded as highly active, while compounds with an inhibitory activity of at least $60 \%$ were considered to be moderately active. The identity of the compounds and the screening results are available as supplementary material (Table S2). Overall, 77 compounds were able to prevent biofilm formation by at least $80 \%$ (according to both the resazurin and crystal violet staining). A list of all these hits and their inhibitory activity is provided (Table A1, Appendix A). However, no compound significantly affected pre-formed biofilms, which is not surprising when considering the high chemotolerance of biofilms. Of the 77 positive hits initially identified in pre-exposure, 50 were known antibacterial compounds and seven were known to be anti-infective, which suggests that the screening platform worked well in identifying compounds with previously recognized antibacterial activity. Five other hits were known antifungal compounds: econazole nitrate, amphotericin B, sulconazole nitrate, miconazole nitrate, and phenylmercuric acetate. For some of those, antibacterial activity has already been reported $[43,44]$, but no prior studies have been done on the antibacterial activity of phenylmercuric acetate or sulconazole, at least to be best of our knowledge. It is interesting to note that amphotericin B is generally thought to be inactive on bacteria, arguably either because of the drug's sterol-based mechanism of action or because of the target's membrane structure [45]. Seven additional hits were neoplastic compounds: teniposide, dactinomycin, mitomycin C, floxuridine, celastrol, agelasine, and carmofur. The antibacterial activity of those compounds has been investigated before and some of them seem to hold potential for treatment of bacterial infections, but their high cytotoxicity generally prevents their use as antibiotics [46-51]. Two of the remaining initial hits are anti-helminthic drugs. The first, pyrvinium pamoate, has also been identified in a screening against methicillin-resistant Staphylococcus aureus (MRSA) [52]. The second, niclosamide, has been repeatedly identified in screening campaigns and investigated for its many potential new purposes, including as an antibacterial drug [51,53-55]. The five remaining hits, triamcinolone acetonide, chlorthalidone, physostigmine salicylate, chlorgiline hydrochloride, and chlorpheniramine maleate, were known for diverse functions that were unrelated to antimicrobial treatment. However, after performing new follow-up studies on re-purchased compounds, their antibacterial activity could not be confirmed, and these hits were not pursued any further. 


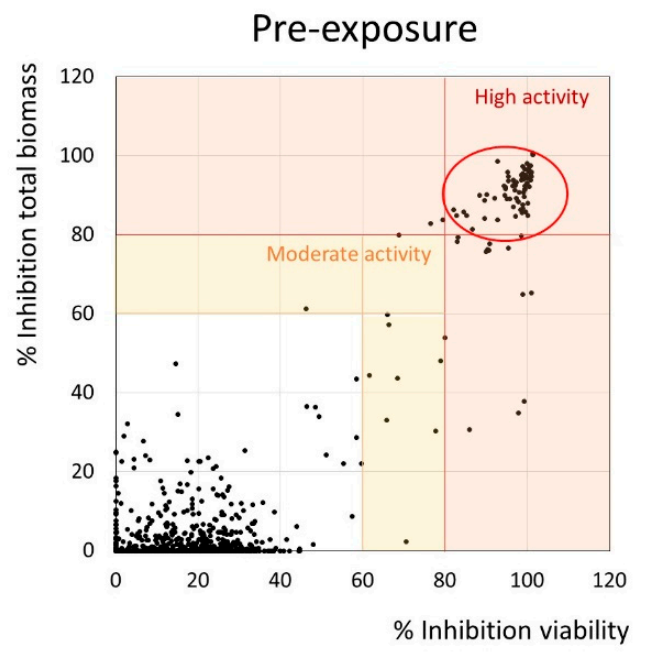

(a)

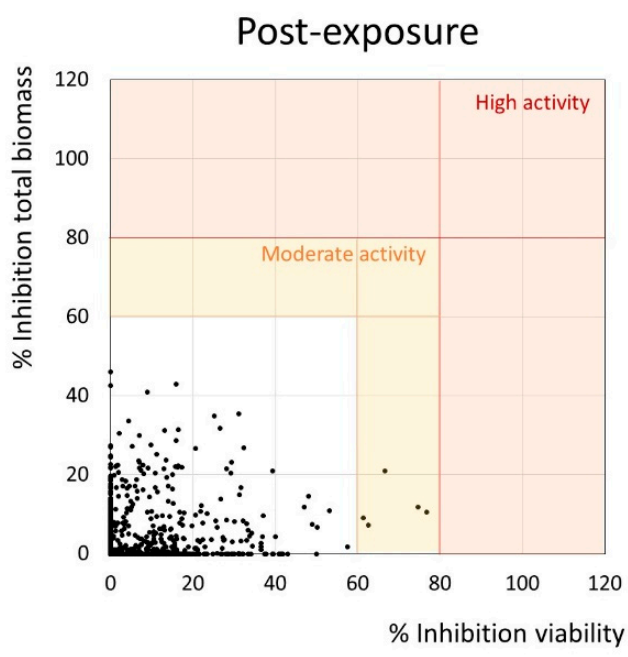

(b)

Figure 9. Results of the screening of a compound library of 2000 compounds tested at $10 \mu \mathrm{M}$ against S. aureus biofilms grown in 384WP. (a): prevention of biofilm formation (pre-exposure). (b): destruction of 18h-old pre-formed biofilms (post-exposure). The effect of the compounds on the biofilms was assessed by resazurin ( $x$ axis) and crystal violet (y axis) staining. The red lines represent the inhibition thresholds used to select active compounds. Results are expressed as inhibition percentages of viability or biomass in comparison to untreated biofilms and they are based on two independent biological replica experiments.

\section{Materials and Methods}

\subsection{Bacterial Growth and Biofilm Formation}

The biofilm-producing strains of S. aureus ATCC 25,923 (Faculty of Pharmacy, University of Helsinki, Helsinki, Finland) and P. aeruginosa ATCC 15,442 (provided by the Laboratory of Microbiology, Parasitology and Hygiene (LMPH), University of Antwerp, Antwerpen, Belgium) were seeded on tryptic soy agar (TSA) (LAB011, Lab M Ltd., Heywood, United Kingdom) and grown overnight under aerobic conditions at $37{ }^{\circ} \mathrm{C}$. The bacteria were then suspended in $5 \mathrm{~mL}$ of tryptic soy broth (TSB) (LAB004, Lab M Ltd.) and grown to exponential phase under aerobic conditions at $37^{\circ} \mathrm{C}$ with shaking $(220 \mathrm{rpm})$ until the cells reached approximately $4.00 \times 10^{8} \mathrm{CFU}$ (Colony Forming Unit) $\mathrm{mL}^{-1}$ for S. aureus and $1.00 \times 10^{9} \mathrm{CFU} \mathrm{mL}^{-1}$ for P. aeruginosa. The biofilms were formed in polystyrene 384WP (Nunc ${ }^{\mathrm{TM}}$ 242757, Thermo Fisher Scientific, Roskilde, Denmark) or 96WP (Nunc ${ }^{\mathrm{TM}}$ 161093, Thermo Fisher Scientific, Roskilde, Denmark) from various dilutions (for $S$. aureus: $4.00 \times 10^{6} \mathrm{CFU} \mathrm{mL}^{-1}, 2.50 \times 10^{6} \mathrm{CFU} \mathrm{mL}^{-1}, 7.00 \times 10^{5} \mathrm{CFU} \mathrm{mL}^{-1}$, $7.00 \times 10^{4} \mathrm{CFU} \mathrm{mL}^{-1}$, and $7.00 \times 10^{3} \mathrm{CFU} \mathrm{mL}^{-1}$; for $P$. aeruginosa: $1.00 \times 10^{7} \mathrm{CFU} \mathrm{mL}^{-1}$, $6.25 \times 10^{6} \mathrm{CFU} \mathrm{mL}^{-1}, 1.75 \times 10^{6} \mathrm{CFU} \mathrm{mL}^{-1}, 1.75 \times 10^{5} \mathrm{CFU} \mathrm{mL}^{-1}$, and $1.75 \times 10^{4} \mathrm{CFU} \mathrm{mL}^{-1}$ ) of the initial bacterial suspension. For each species, the plates were incubated for $18 \mathrm{~h}$ or $42 \mathrm{~h}$ under aerobic conditions at $37^{\circ} \mathrm{C}, 220 \mathrm{rpm}$. For the $42 \mathrm{~h}$-old biofilms, the media was changed after $18 \mathrm{~h}$ of incubation.

\subsection{Resazurin Staining}

The resazurin staining was performed, as described earlier [15], with some modifications. Briefly, the planktonic solution was discarded very gently, attempting to minimize any disruptions to the biofilms. The biofilms were washed once with a working volume (either $40 \mu \mathrm{L}$ or $50 \mu \mathrm{L}$ in $384 \mathrm{WP}$ or $200 \mu \mathrm{L}$ in 96WP) of phosphate buffered saline (PBS) (BR0014, Thermo Fisher Scientific, Basingstoke, England). The washed biofilm cells were incubated with different concentrations of resazurin (20, 40, $60,80,100$, and $200 \mu \mathrm{M}$ ) in the darkness at room temperature (RT) or at $37^{\circ} \mathrm{C}$ (when indicated), with agitation (220 rpm) for various periods of time (S. aureus: 5, 10, 20, 30, and $40 \mathrm{~min}$; P. aeruginosa: 5, 10, 
20, 30, 40, 60, and 80 min.). The resazurin sodium salt (R7017, Sigma-Aldrich, St. Louis, MO, USA) was dissolved in PBS to obtain a stock solution of $400 \mu \mathrm{M}$ (or $0.1 \mathrm{mg} \mathrm{mL}^{-1}$ ), which was subsequently diluted in PBS to achieve the indicated concentrations for staining the biofilm cells. Fluorescence was measured at $\lambda_{\text {excitation }}=560 \mathrm{~nm}$ and $\lambda_{\text {emission }}=590 \mathrm{~nm}$ while using the top optics of the Varioskan LUX Multimode microplate reader (Thermo Scientific, Vantaa, Finland). After the measurement, the resazurin solution was removed from the wells, and the biofilms were stained with crystal violet, as follows.

\subsection{Crystal Violet Staining}

After resazurin staining, biofilms were subsequently stained with crystal violet as previously reported [14]. To fix the biofilms, a working volume of ethanol $100 \%$ (either $40 \mu \mathrm{L}$ or $50 \mu \mathrm{L}$ in $384 \mathrm{WP}$ or $200 \mu \mathrm{L}$ in $96 \mathrm{WP}$ ) was added onto the biofilms and the $96 \mathrm{WP} / 384 \mathrm{WP}$ plates were incubated at RT. After $15 \mathrm{~min}$. the lids were removed, and wells were allowed to air-dry completely. The biofilms were stained with various concentrations $(0.023 \%, 0.1 \%, 0.23 \%, 1 \% v / v)$ of crystal violet (HT90132, Sigma-Aldrich, St. Louis, MO, USA) at RT for five minutes and then washed twice with deionized $\mathrm{H}_{2} \mathrm{O}$ and left to dry a few minutes ( $5 \mathrm{~min}$. for $96 \mathrm{WP}$, up to $10 \mathrm{~min}$. for $384 \mathrm{WP}$ ). The crystal violet bound to the biofilms was solubilized in $96 \%$ ethanol for $1 \mathrm{~h}$ at RT. The absorbance was measured at $595 \mathrm{~nm}$ with a Multiskan Sky microplate spectrophotometer (Thermo Scientific, Vantaa, Finland).

\subsection{Comparing the CFUs of Biofilms formed in $384 W P$ and $96 \mathrm{WP}$}

The biofilms of S. aureus and P. aeruginosa were grown in both 96WP and 384WP, as described previously. The bacteria were seeded in the wells at a concentration of $4.00 \times 10^{6} \mathrm{CFU} \mathrm{mL}^{-1}$ (S. aureus) or $1.00 \times 10^{7} \mathrm{CFU} \mathrm{mL}^{-1}$ (P. aeruginosa) in $96 \mathrm{WP}$ and $7.00 \times 10^{4} \mathrm{CFU} \mathrm{mL}^{-1}$ (S. aureus) or $1.75 \times 10^{5} \mathrm{CFU} \mathrm{mL}^{-1}$ (P. aeruginosa) in 384WP. The concentration of the bacterial cells selected for 384WP was based on the obtained results during the optimization steps. After $18 \mathrm{~h}$ or $42 \mathrm{~h}$, the planktonic bacteria were discarded, and biofilms were washed once with a working volume of PBS. The biofilms were then scraped using a pipette tip in either $20 \mu \mathrm{L}$ (384WP) or $100 \mu \mathrm{L}$ (96WP) of PBS and clumps were thoroughly broken by repeated pipetting. The bacteria were serially diluted in PBS and $10 \mu \mathrm{L}$ drops of the dilutions $\left(10^{-4}\right.$ to $\left.10^{-7}\right)$ were spotted on TSA to measure the formation of viable colonies.

\subsection{Comparing the Antibiotic Susceptibility of S. aureus Biofilms in 384WP and 96WP}

A small panel of four well-characterized antibiotics (penicillin, rifampicin, oxacillin, and doxycycline; Sigma-Aldrich, St. Louis, MO, USA), with diverse chemotypes and three different mechanisms of action, were tested against $S$. aureus (Scheme 1). For that purpose, the antibiotics were dissolved in dimethyl sulfoxide (DMSO) (34943, Sigma-Aldrich, St. Louis, MO, USA) to obtain a stock solution of $20 \mathrm{mM}$. The tested antibiotics were further dissolved in DMSO is such a way that the final concentration of DMSO did not exceed $2.5 \%(v / v)$. A pre-exposure mode was used in which the antibiotics ( $1 \mu \mathrm{L}$ per well in $384 \mathrm{WP}$ and $5 \mu \mathrm{L}$ per well in $96 \mathrm{WP})$ were added into the wells at the same time with the bacterial suspensions. The following parameters were used: (i) the total working volume for $384 \mathrm{WP}$ was $40 \mu \mathrm{L}$ and $200 \mu \mathrm{L}$ for $96 \mathrm{WP}$, (ii) for $384 \mathrm{WP}$ the added concentration of suspended cells was $7.00 \times 10^{4} \mathrm{CFU} \mathrm{mL}{ }^{-1}$, whereas a higher concentration of added suspended cells $\left(4.00 \times 10^{6} \mathrm{CFU} \mathrm{mL}{ }^{-1}\right)$ was used for $96 \mathrm{WP}$. The inhibition capacity of the indicated antibiotics at different concentrations was measured after $18 \mathrm{~h}$ whlie using the resazurin $(20 \mu \mathrm{M}, 30 \mathrm{~min}$.) and crystal violet assays, as described above. 


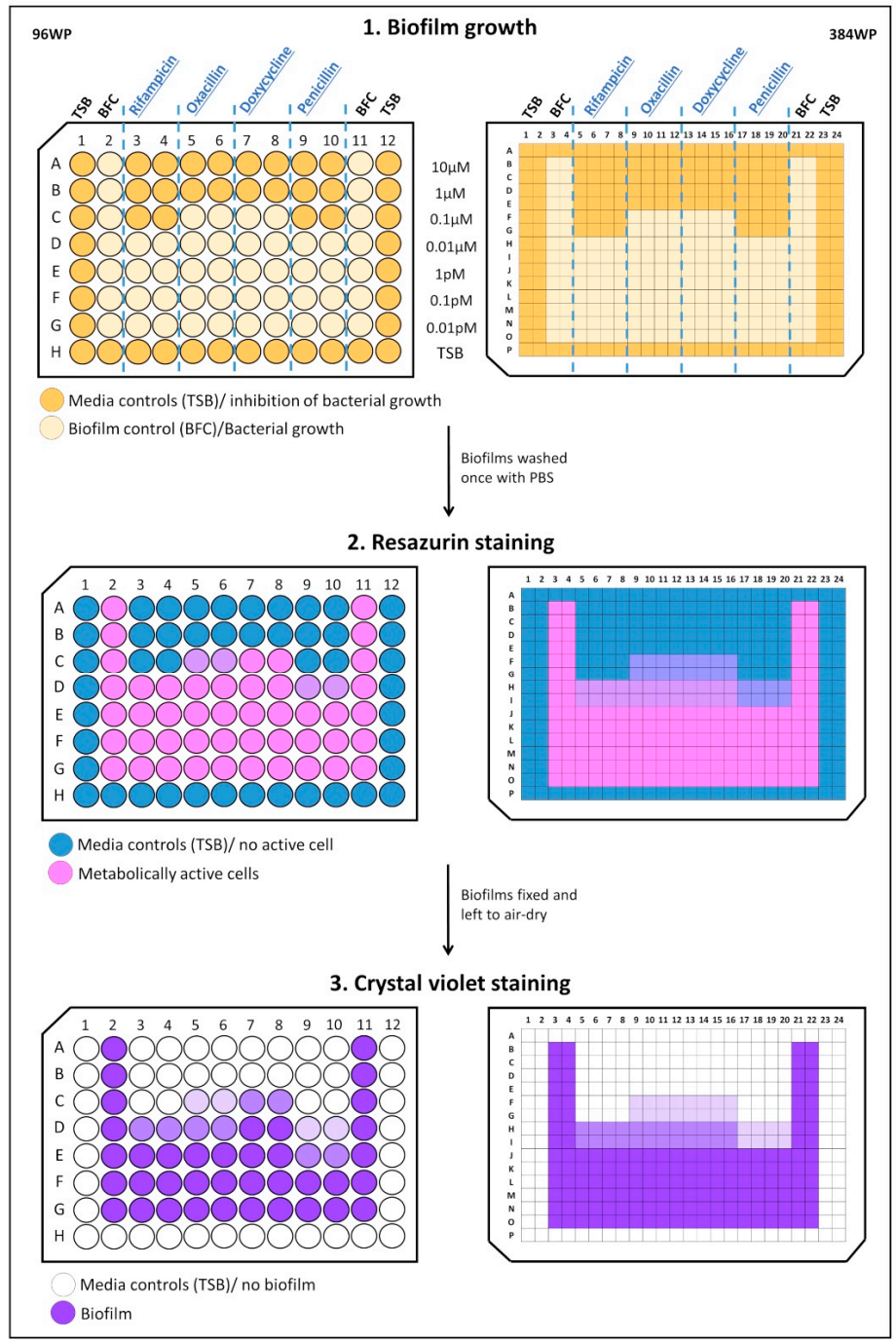

Scheme 1. Workflow used for comparing the inhibition of $S$. aureus growth with a panel of four model antibiotics using the pre-exposure mode in 96WP and 384WP.

\subsection{Pilot Screening Against S. aureus Biofilms in $384 \mathrm{WP}$ and $96 \mathrm{WP}$}

A total of 100 compounds were tested on S. aureus biofilms grown in 96WP and 384WP platforms. Eighty-eight of them were from a natural derivatives collection (NDL-3000, TimTec Inc., Newark, DE, USA), two were provided by the medicinal chemistry group (Division of Pharmaceutical Chemistry and Technology, Faculty of Pharmacy, University of Helsinki, Helsinki, Finland), and were synthesized, as described in [56]. The remaining 10 were well-known antibiotics, included for control purposes. All of the compounds were dissolved in DMSO:PBS $(1: 1, v / v)$ to a concentration of $400 \mu \mathrm{M}$. One $\mu \mathrm{L}$ per well $(384 \mathrm{WP}$ ) or $5 \mu \mathrm{L}$ per well (96WP) of compound (at a final concentration of $10 \mu \mathrm{M}$ ) were added to the test plates in a final working volume of $40 \mu \mathrm{L}$ in $384 \mathrm{WP}$ and $200 \mu \mathrm{l}$ in $96 \mathrm{WP}$. The screening was performed using the pre-exposure (antibiotics added at the same time as the bacteria, cells with compounds cultured for $18 \mathrm{~h}$ ) and post-exposure (antibiotics added onto $18 \mathrm{~h}$-old biofilms, cells with compounds incubated for $24 \mathrm{~h}$ ) modes. The $S$. aureus inoculum concentration was $7.00 \times 10^{4} \mathrm{CFU} \mathrm{mL}^{-1}$ in $384 \mathrm{WP}$ and $4.00 \times 10^{6} \mathrm{CFU} \mathrm{mL} \mathrm{m}^{-1}$ in $96 \mathrm{WP}$. The effect of the compounds was assessed while using the resazurin $(20 \mu \mathrm{M}$ in pre-exposure and $40 \mu \mathrm{M}$ in post-exposure, $30 \mathrm{~min}$. incubation at RT in darkness, $220 \mathrm{rpm})$ and crystal violet $(0.023 \%, v / v), 5 \mathrm{~min}$. incubation, $1 \mathrm{~h}$ dissolution in EtOH at RT) staining assays, as described above. The list of all tested compounds, sources, and their screening results in 96WP and 384WP is available in the Supplementary Table S1. 


\subsection{Screening of a Compound Library against S. aureus}

The commercially available Microsource Spectrum Collection (Discovery Systems Inc., Gaylordsville, CT, USA) was screened on $S$. aureus biofilms that were grown in 384WP. The 2000 compounds were received as dry powders and solubilized in DMSO:PBS (1:1, v/v) to a concentration of $200 \mu \mathrm{M}$. Two $\mu \mathrm{L}$ per well of compound were added to the test plates in a final working volume of $40 \mu \mathrm{L}$ (for a final concentration of $10 \mu \mathrm{M}$ ). As for the pilot screening, the screening was performed while using the pre-exposure and post-exposure modes and the S. aureus inoculum concentration was $7.00 \times 10^{4} \mathrm{CFU} \mathrm{mL}^{-1}$. The wells were treated, as described in Section 2.6, using the resazurin and crystal violet staining assays to measure the effect on biofilms viability. The list of all tested compounds, sources and their screening results in $384 \mathrm{WP}$ is available in the Supplementary Materials (Table S2).

\subsection{Statistical Analysis}

The inhibition results of bacterial growth by antibiotics are shown as the percent of control \pm S.D. (standard deviation). The assay performance was monitored using the screening window coefficient $Z^{\prime}$ factor $\left(Z^{\prime}\right.$, Equation (1)) and the signal-to-noise (S/N, Equation (2)), calculated with the following equations, according to [36,57], respectively:

$$
\begin{gathered}
Z^{\prime}=(1-(3 \times \text { s.d.max } \\
\left.S / N=\left(X_{\max }-X_{\min }\right) / \sqrt{ }\left(\text { s.d.d.max }{ }_{\text {man }}\right)\right) /\left(X_{\max }-X_{\min }\right) \\
\text { s.d.min } \left.{ }^{2}\right)
\end{gathered}
$$

$X_{\min }$ and s.d.min are the average and the standard deviation of the readings that were obtained in media controls (wells containing only sterile TSB) and $X_{\max }$ and s.d.max are the average and standard deviation of the readings obtained in biofilm controls (wells containing untreated bacteria).

\section{Conclusions}

In this work, we have miniaturized an antibacterial screening platform combining the resazurin and crystal violet staining into 384WP format while using two different bacterial species, S. aureus and $P$. aeruginosa, as gram-positive and gram-negative biofilm-forming models, respectively. The method was optimized in terms of initial bacterial cell concentrations, working volumes, the resazurin and crystal violet concentrations, and incubation times. Despite a slightly higher well-to-well variability detected in 384WP when compared to 96WP, we show that the miniaturized platform produces high quality results and that the resazurin staining and crystal violet staining can be easily applied to 384WP to study changes in bacterial biofilm formation. Through antibacterial challenges and a validatory small-scale pilot screen, we also showed that the obtained results are comparable to those obtained in 96WP, making this miniaturized platform suitable for the large-scale screening of antimicrobial compounds. A screening of 2000 compounds using this platform further confirmed its applicability. Although no new compounds worth taking further as a lead candidate were identified, interesting observations were made on many compounds that are not presently used as antibiotics, and our results were confirmative of earlier findings that were made during other screening studies. Other parameters, including the shaking speed during the incubation, which can affect biofilm formation and tolerance, were not studied here. The effect of the smaller working volume and the shape of the wells in the 384WP on the distribution of nutrients and oxygen and, thereby, the overall architecture of the biofilms, also remains to be studied. Nevertheless, our screening campaign, by indicating many previously identified compounds, strengthens the applicability of the optimized 384 platform in the reliable identification of new antibacterial compounds. In addition, this platform was shown to allow the testing of four-times the number of compounds in a single run as compared to 96WP with less amount of materials needed. In conclusion, the optimized 384WP platform demonstrates that resazurin and crystal violet can be applied for high-throughput anti-biofilm screening in 384WP. 
Supplementary Materials: Supplementary Materials can be found at http://www.mdpi.com/1422-0067/21/9/3034/ s1. Table S1: Compounds identification and inhibition results of the pilot screening performed on S. aureus biofilms in 96WP and 384WP. Table S2: Identification of the compounds from the Microsource Spectrum Collection (Discovery Systems Inc., Houston, TX, USA) and results of the screening performed on S. aureus planktonic cells and biofilms in 384WP. Figure S1: Correlation of the $Z^{\prime}$ factor and the signal-to-noise $(\mathrm{S} / \mathrm{N})$ statistical parameters throughout the optimization process. Figure S2: Folds of the $Z^{\prime}$ factor and the Max-Min value obtained for the crystal violet assay after different incubation periods of the dye in the wells and different dissolution periods in ethanol.

Author Contributions: Conceptualization, S.G.-G. and A.F.; methodology, S.G.-G. and A.F.; formal analysis, S.G.-G.; investigation, S.G.-G.; resources, A.F.; writing-original draft preparation, S.G.-G.; writing-review and editing, S.G.-G., K.S., J.Y.-K. and A.F.; supervision, K.S., J.Y.-K. and A.F.; funding acquisition, J.Y.-K. and A.F. All authors have read and agreed to the published version of the manuscript.

Funding: This research was funded by the European Union's Horizon 2020 research and innovation programme under the Marie Skłodowska-Curie grant agreement number 722467. Financial support received from the Jane and Aatos Erkko Foundation is also greatly appreciated.

Conflicts of Interest: The authors declare no conflict of interest. The funders had no role in the design of the study; in the collection, analyses, or interpretation of data; in the writing of the manuscript, or in the decision to publish the results.

\begin{tabular}{ll}
\multicolumn{2}{l}{ Abbreviations } \\
ATCC & American Type Culture Collection \\
CFU & Colony-forming unit \\
DMSO & Dimethyl sulfoxide \\
HTS & High-throughput screening \\
MDPI & Multidisciplinary Digital Publishing Institute \\
MIC & Minimum inhibitory concentration \\
MoA & Mode of action \\
OD & Optical density \\
PBS & Phosphate buffered saline \\
Rpm & Revolutions per minute \\
RT & Room temperature \\
S.D. & Standard deviation \\
S/N & Signal-to-noise \\
TSA & Tryptic soy agar \\
TSB & Tryptic soy broth \\
96WP & 96-well plate \\
384WP & 384-well plate \\
Z' & Z' factor
\end{tabular}

\section{Appendix A}

Table A1. Hits preventing over $80 \%$ of S. aureus biofilm formation from the screening of 2000 compounds from the Microsource Spectrum Collection (Discovery Systems Inc.).

\begin{tabular}{cccc}
\hline \multirow{2}{*}{ Compound Name } & \multicolumn{2}{c}{ \% Inhibition Biofilm Formation } & \multirow{2}{*}{ Main Known Function ${ }^{{ }^{*}}$} \\
\cline { 2 - 3 } & Viability & Biomass & \\
\hline CETYLPYRIDINIUM CHLORIDE & 99 & 95 & anti-infective \\
\hline MINOCYCLINE HYDROCHLORIDE & 95 & 92 & antibacterial \\
\hline ECONAZOLE NITRATE & 94 & 92 & antifungal \\
\hline NOVOBIOCIN SODIUM & 99 & 90 & antibacterial \\
\hline MECLOCYCLINE SULFOSALICYLATE & 97 & 93 & antibacterial \\
\hline TENIPOSIDE & 97 & 91 & antineoplastic \\
\hline AZLOCILLIN SODIUM & 99 & 92 & antibacterial \\
\hline AMPHOTERICIN B & 95 & 94 & antifungal
\end{tabular}


Table A1. Cont.

\begin{tabular}{|c|c|c|c|}
\hline \multirow{2}{*}{ Compound Name } & \multicolumn{2}{|c|}{$\%$ Inhibition Biofilm Formation } & \multirow{2}{*}{ Main Known Function $^{1}$} \\
\hline & Viability & Biomass & \\
\hline LOMEFLOXACIN HYDROCHLORIDE & 85 & 86 & antibacterial \\
\hline CEFAMANDOLE SODIUM & 99 & 94 & antibacterial \\
\hline NAFCILLIN SODIUM & 99 & 92 & antibacterial \\
\hline DACTINOMYCIN & 101 & 96 & antineoplastic \\
\hline DIRITHROMYCIN & 100 & 94 & antibacterial \\
\hline MITOMYCIN C & 83 & 85 & antineoplastic \\
\hline RIFAXIMIN & 98 & 88 & antibacterial \\
\hline CHLORHEXIDINE & 82 & 86 & antibacterial, disinfectant \\
\hline NORFLOXACIN & 99 & 94 & antibacterial \\
\hline OFLOXACIN & 95 & 95 & antibacterial \\
\hline METHACYCLINE HYDROCHLORIDE & 99 & 94 & antibacterial \\
\hline BENZETHONIUM CHLORIDE & 101 & 95 & anti-infective \\
\hline CEPHALOTHIN SODIUM & 99 & 88 & antibacterial \\
\hline SULCONAZOLE NITRATE & 95 & 92 & antifungal \\
\hline GEMIFLOXACIN MESYLATE & 97 & 93 & antibacterial \\
\hline THIMEROSAL & 98 & 91 & $\begin{array}{l}\text { anti-infective, } \\
\text { preservative }\end{array}$ \\
\hline PENICILLIN G POTASSIUM & 96 & 92 & antibacterial \\
\hline RIFAMPIN & 101 & 95 & antibacterial \\
\hline TRIAMCINOLONE ACETONIDE & 90 & 90 & anti-inflammatory \\
\hline HETACILLIN POTASSIUM & 99 & 80 & antibacterial \\
\hline CHLORPHENIRAMINE (S) MALEATE & 80 & 84 & antihistaminic \\
\hline PENICILLIN V POTASSIUM & 98 & 88 & antibacterial \\
\hline CLINDAMYCIN HYDROCHLORIDE & 99 & 97 & antibacterial \\
\hline HEXACHLOROPHENE & 95 & 89 & anti-infective \\
\hline GENTIAN VIOLET & 100 & 92 & $\begin{array}{l}\text { antibacterial, } \\
\text { anti-helminthic }\end{array}$ \\
\hline PYRVINIUM PAMOATE & 99 & 94 & anti-helminthic \\
\hline MICONAZOLE NITRATE & 88 & 90 & antifungal \\
\hline $\begin{array}{l}\text { CHLORTETRACYCLINE } \\
\text { HYDROCHLORIDE }\end{array}$ & 96 & 89 & antibacterial, anti-amebic \\
\hline DICLOXACILLIN SODIUM & 101 & 96 & antibacterial \\
\hline LINCOMYCIN HYDROCHLORIDE & 92 & 89 & antibacterial \\
\hline CHLORTHALIDONE & 98 & 86 & $\begin{array}{c}\text { diuretic, } \\
\text { antihypertensive }\end{array}$ \\
\hline PHYSOSTIGMINE SALICYLATE & 99 & 86 & cholinergic, miotic \\
\hline CLOXACILLIN SODIUM & 97 & 87 & antibacterial \\
\hline PHENYLMERCURIC ACETATE & 99 & 95 & antifungal \\
\hline ERYTHROMYCIN ETHYLSUCCINATE & 99 & 92 & antibacterial \\
\hline FURAZOLIDONE & 97 & 94 & antibacterial \\
\hline TRIMETHOPRIM & 85 & 85 & antibacterial \\
\hline FUSIDIC ACID & 95 & 92 & antibacterial \\
\hline VANCOMYCIN HYDROCHLORIDE & 95 & 96 & antibacterial \\
\hline PHENETHICILLIN POTASSIUM & 100 & 85 & antibacterial \\
\hline ROXITHROMYCIN & 99 & 94 & antibacterial \\
\hline
\end{tabular}


Table A1. Cont.

\begin{tabular}{|c|c|c|c|}
\hline \multirow{2}{*}{ Compound Name } & \multicolumn{2}{|c|}{$\%$ Inhibition Biofilm Formation } & \multirow{2}{*}{ Main Known Function ${ }^{1}$} \\
\hline & Viability & Biomass & \\
\hline MOXIFLOXACIN HYDROCHLORIDE & 90 & 84 & antibacterial \\
\hline CEFTIBUTEN & 100 & 93 & antibacterial \\
\hline BACAMPICILLIN HYDROCHLORIDE & 100 & 98 & antibacterial \\
\hline TYLOSIN TARTRATE & 99 & 96 & antibacterial \\
\hline RETINYL PALMITATE & 100 & 95 & provitamin \\
\hline FLOXURIDINE & 100 & 86 & antineoplastic \\
\hline CEFDINIR & 101 & 98 & antibacterial \\
\hline SARAFLOXACIN HYDROCHLORIDE & 93 & 84 & antibacterial \\
\hline TRICLOSAN & 101 & 94 & anti-infective \\
\hline TELITHROMYCIN & 100 & 88 & antibacterial \\
\hline NICLOSAMIDE & 87 & 81 & anthelmintic, teniacide \\
\hline LEVOFLOXACIN & 97 & 89 & antibacterial \\
\hline CIPROFLOXACIN & 97 & 93 & antibacterial, fungicide \\
\hline TICARCILLIN DISODIUM & 101 & 100 & antibacterial \\
\hline TILMICOSIN & 101 & 101 & antibacterial \\
\hline GATIFLOXACIN & 93 & 99 & antibacterial \\
\hline METHYLBENZETHONIUM CHLORIDE & 99 & 91 & anti-infective \\
\hline AZITHROMYCIN & 100 & 97 & antibacterial \\
\hline MUPIROCIN & 100 & 97 & antibacterial \\
\hline PEFLOXACINE MESYLATE & 99 & 95 & antibacterial \\
\hline TEICOPLANIN & 99 & 94 & antibacterial \\
\hline ERYTHROMYCIN STEARATE & 97 & 93 & antibacterial \\
\hline CETRIMONIUM BROMIDE & 95 & 90 & anti-infective \\
\hline CLORGILINE HYDROCHLORIDE & 99 & 87 & antidepressant \\
\hline CELASTROL & 100 & 96 & antineoplastic \\
\hline FLORFENICOL & 97 & 85 & antibacterial \\
\hline AGELASINE & 100 & 96 & antineoplastic \\
\hline CARMOFUR & 90 & 89 & antineoplastic \\
\hline
\end{tabular}

\section{References}

1. Olson, M.E.; Ceri, H.; Morck, D.W.; Buret, A.G.; Read, R.R. Biofilm bacteria: Formation and comparative susceptibility to antibiotics. Can. J. Vet. Res. Rev. Can. De. Rech. Vet. 2002, 66, 86-92.

2. Anwar, H.; Dasgupta, M.K.; Costerton, J.W. Testing the susceptibility of bacteria in biofilms to antibacterial agents. Antimicrob. Agents Chemother. 1990, 34, 2043-2046. [CrossRef] [PubMed]

3. Davies, D. Understanding biofilm resistance to antibacterial agents. Nat. Rev. Drug Discov. 2003, 2, 114-122. [CrossRef]

4. Roberts, A.E.; Kragh, K.N.; Bjarnsholt, T.; Diggle, S.P. The Limitations of In Vitro Experimentation in Understanding Biofilms and Chronic Infection. J. Mol. Biol. 2015, 427, 3646-3661. [CrossRef] [PubMed]

5. Costerton, J.W.; Lewandowski, Z.; Caldwell, D.E.; Korber, D.R.; Lappin-Scott, H.M. Microbial biofilms. Annu. Rev. Microbiol. 1995, 49, 711-745. [CrossRef]

6. Costerton, J.W.; Stewart, P.S.; Greenberg, E.P. Bacterial biofilms: A common cause of persistent infections. Science 1999, 284, 1318-1322. [CrossRef]

7. Mah, T.F.; O'Toole, G.A. Mechanisms of biofilm resistance to antimicrobial agents. Trends Microbiol. 2001, 9, 34-39. [CrossRef] 
8. Stewart, P.S.; Franklin, M.J. Physiological heterogeneity in biofilms. Nat. Rev. Microbiol. 2008, 6, $199-210$. [CrossRef]

9. Zimmerli, W.; Moser, C. Pathogenesis and treatment concepts of orthopaedic biofilm infections. Fems Immunol. Med. Microbiol. 2012, 65, 158-168. [CrossRef]

10. Boucher, H.W.; Talbot, G.H.; Bradley, J.S.; Edwards, J.E.; Gilbert, D.; Rice, L.B.; Scheld, M.; Spellberg, B.; Bartlett, J. Bad bugs, no drugs: No eskape! An update from the Infectious Diseases Society of America. Clin. Infect. Dis. 2009, 48, 1-12. [CrossRef]

11. Spellberg, B.; Guidos, R.; Gilbert, D.; Bradley, J.; Boucher, H.W.; Scheld, W.M.; Bartlett, J.G.; Edwards, J., Jr. The epidemic of antibiotic-resistant infections: A call to action for the medical community from the Infectious Diseases Society of America. Clin. Infect. Dis. 2008, 46, 155-164. [CrossRef] [PubMed]

12. Mantravadi, P.K.; Kalesh, K.A.; Dobson, R.C.J.; Hudson, A.O.; Parthasarathy, A. The Quest for Novel Antimicrobial Compounds: Emerging Trends in Research, Development, and Technologies. Antibiotics 2019, 8, 8. [CrossRef] [PubMed]

13. Peeters, E.; Nelis, H.J.; Coenye, T. Comparison of multiple methods for quantification of microbial biofilms grown in microtiter plates. J. Microbiol. Methods 2008, 72, 157-165. [CrossRef] [PubMed]

14. Sandberg, M.; Maattanen, A.; Peltonen, J.; Vuorela, P.M.; Fallarero, A. Automating a 96-well microtitre plate model for Staphylococcus aureus biofilms: An approach to screening of natural antimicrobial compounds. Int. J. Antimicrob. Agents 2008, 32, 233-240. [CrossRef]

15. Sandberg, M.E.; Schellmann, D.; Brunhofer, G.; Erker, T.; Busygin, I.; Leino, R.; Vuorela, P.M.; Fallarero, A. Pros and cons of using resazurin staining for quantification of viable Staphylococcus aureus biofilms in a screening assay. J. Microbiol. Methods 2009, 78, 104-106. [CrossRef]

16. Donne, J.; Dewilde, S. The Challenging World of Biofilm Physiology. Adv. Microb. Physiol. 2015, 67, $235-292$. [CrossRef]

17. Manner, S.; Goeres, D.M.; Skogman, M.; Vuorela, P.; Fallarero, A. Prevention of Staphylococcus aureus biofilm formation by antibiotics in 96-Microtiter Well Plates and Drip Flow Reactors: Critical factors influencing outcomes. Sci. Rep. 2017, 7, 43854. [CrossRef]

18. Tote, K.; Vanden Berghe, D.; Maes, L.; Cos, P. A new colorimetric microtitre model for the detection of Staphylococcus aureus biofilms. Lett. Appl. Microbiol. 2008, 46, 249-254. [CrossRef]

19. Rajamani, S.; Sandy, R.; Kota, K.; Lundh, L.; Gomba, G.; Recabo, K.; Duplantier, A.; Panchal, R.G. Robust biofilm assay for quantification and high throughput screening applications. J. Microbiol. Methods 2019, 159, 179-185. [CrossRef]

20. Stepanovic, S.; Vukovic, D.; Dakic, I.; Savic, B.; Svabic-Vlahovic, M. A modified microtiter-plate test for quantification of staphylococcal biofilm formation. J. Microbiol. Methods 2000, 40, 175-179. [CrossRef]

21. Burton, E.; Yakandawala, N.; LoVetri, K.; Madhyastha, M.S. A microplate spectrofluorometric assay for bacterial biofilms. J. Ind. Microbiol. Biotechnol. 2007, 34, 1-4. [CrossRef] [PubMed]

22. Stiefel, P.; Rosenberg, U.; Schneider, J.; Mauerhofer, S.; Maniura-Weber, K.; Ren, Q. Is biofilm removal properly assessed? Comparison of different quantification methods in a 96-well plate system. Appl. Microbiol. Biotechnol. 2016, 100, 4135-4145. [CrossRef] [PubMed]

23. Pitts, B.; Hamilton, M.A.; Zelver, N.; Stewart, P.S. A microtiter-plate screening method for biofilm disinfection and removal. J. Microbiol. Methods 2003, 54, 269-276. [CrossRef]

24. Skogman, M.E.; Vuorela, P.M.; Fallarero, A. Combining biofilm matrix measurements with biomass and viability assays in susceptibility assessments of antimicrobials against Staphylococcus aureus biofilms. J. Antibiot. 2012, 65, 453-459. [CrossRef] [PubMed]

25. Li, X.; Yan, Z.; Xu, J. Quantitative variation of biofilms among strains in natural populations of Candida albicans. Microbiology 2003, 149, 353-362. [CrossRef]

26. Campbell, J. High-throughput assessment of bacterial growth inhibition by optical density measurements. Curr. Protoc. Chem. Biol. 2011, 3. [CrossRef]

27. Mishra, A.; Dobritsa, S.V.; Crouch, M.L.; Rabenstein, J.; Lee, J.X.; Dhakshinamoorthy, S. Establishment and validation of a 384-well antibacterial assay amenable for high-throughput screening and combination testing. J. Microbiol. Methods 2015, 118, 173-175. [CrossRef]

28. Kim, H.J.; Jang, S. Optimization of a resazurin-based microplate assay for large-scale compound screenings against Klebsiella pneumoniae. 3 Biotech 2018, 8, 3. [CrossRef] 
29. Foerster, S.; Gustafsson, T.N.; Rita Brochado, A.; Desilvestro, V.; Typas, A.; Unemo, M. The first wide-scale drug repurposing screen using the Prestwick Chemical Library (1200 bioactive molecules) against Neisseria gonorrhoeae identifies high in vitro activity of auranofin and many additional drugs. Apmis. Acta Pathol. Microbiol. Immunol. Scand. 2019. [CrossRef]

30. Gavrish, E.; Shrestha, B.; Chen, C.; Lister, I.; North, E.J.; Yang, L.; Lee, R.E.; Han, A.; Williams, B.; Charnuska, D.; et al. In vitro and in vivo activities of HPi1, a selective antimicrobial against Helicobacter pylori. Antimicrob. Agents Chemother. 2014, 58, 3255-3260. [CrossRef]

31. Kim, H.J.; Kim, N.; Shum, D.; Huddar, S.; Park, C.M.; Jang, S. Identification of Antipneumococcal Molecules Effective Against Different Streptococcus pneumoniae Serotypes Using a Resazurin-Based High-Throughput Screen. Assay Drug Dev. Technol. 2017, 15, 198-209. [CrossRef] [PubMed]

32. Mak, P.A.; Santos, G.F.; Masterman, K.A.; Janes, J.; Wacknov, B.; Vienken, K.; Giuliani, M.; Herman, A.E.; Cooke, M.; Mbow, M.L.; et al. Development of an automated, high-throughput bactericidal assay that measures cellular respiration as a survival readout for Neisseria meningitidis. Clin. Vaccine Immunol. 2011, 18, 1252-1260. [CrossRef] [PubMed]

33. Navarro, G.; Cheng, A.T.; Peach, K.C.; Bray, W.M.; Bernan, V.S.; Yildiz, F.H.; Linington, R.G. Image-based 384-well high-throughput screening method for the discovery of skyllamycins A to C as biofilm inhibitors and inducers of biofilm detachment in Pseudomonas aeruginosa. Antimicrob. Agents Chemother. 2014, 58, 1092-1099. [CrossRef]

34. LaFleur, M.D.; Lucumi, E.; Napper, A.D.; Diamond, S.L.; Lewis, K. Novel high-throughput screen against Candida albicans identifies antifungal potentiators and agents effective against biofilms. J. Antimicrob. Chem. 2011, 66, 820-826. [CrossRef] [PubMed]

35. Panmanee, W.; Taylor, D.; Shea, C.J.; Tang, H.; Nelson, S.; Seibel, W.; Papoian, R.; Kramer, R.; Hassett, D.J.; Lamkin, T.J. High-throughput screening for small-molecule inhibitors of Staphylococcus epidermidis RP62a biofilms. J. Biomol. Screen. 2013, 18, 820-829. [CrossRef] [PubMed]

36. Zhang, J.H.; Chung, T.D.; Oldenburg, K.R. A Simple Statistical Parameter for Use in Evaluation and Validation of High Throughput Screening Assays. J. Biomol. Screen. 1999, 4, 67-73. [CrossRef] [PubMed]

37. Iversen, P.W.; Eastwood, B.J.; Sittampalam, G.S.; Cox, K.L. A comparison of assay performance measures in screening assays: Signal window, Z' factor, and assay variability ratio. J. Biomol. Screen. 2006, 11, $247-252$. [CrossRef]

38. Merten, C.A. Screening Europe 2010: An update about the latest technologies and applications in high-throughput screening. Expert Rev. Mol. Diagn. 2010, 10, 559-563. [CrossRef]

39. Junker, L.M.; Clardy, J. High-throughput screens for small-molecule inhibitors of Pseudomonas aeruginosa biofilm development. Antimicrob. Agents Chemother. 2007, 51, 3582-3590. [CrossRef]

40. Tote, K.; Berghe, D.V.; Deschacht, M.; de Wit, K.; Maes, L.; Cos, P. Inhibitory efficacy of various antibiotics on matrix and viable mass of Staphylococcus aureus and Pseudomonas aeruginosa biofilms. Int. J. Antimicrob. Agents 2009, 33, 525-531. [CrossRef]

41. O'Brien, J.; Wilson, I.; Orton, T.; Pognan, F. Investigation of the Alamar Blue (resazurin) fluorescent dye for the assessment of mammalian cell cytotoxicity. Eur. J. Biochem. 2000, 267, 5421-5426. [CrossRef] [PubMed]

42. Pantanella, F.; Valenti, P.; Natalizi, T.; Passeri, D.; Berlutti, F. Analytical techniques to study microbial biofilm on abiotic surfaces: Pros and cons of the main techniques currently in use. Ann. Ig. Med. Prev. E Comunita 2013, 25, 31-42. [CrossRef]

43. Qiu, W.; Ren, B.; Dai, H.; Zhang, L.; Zhang, Q.; Zhou, X.; Li, Y. Clotrimazole and econazole inhibit Streptococcus mutans biofilm and virulence in vitro. Arch. Oral. Biol. 2017, 73, 113-120. [CrossRef] [PubMed]

44. Nenoff, P.; Koch, D.; Kruger, C.; Drechsel, C.; Mayser, P. New insights on the antibacterial efficacy of miconazole in vitro. Mycoses 2017, 60, 552-557. [CrossRef] [PubMed]

45. Venegas, B.; Gonzalez-Damian, J.; Celis, H.; Ortega-Blake, I. Amphotericin B channels in the bacterial membrane: Role of sterol and temperature. Biophys. J. 2003, 85, 2323-2332. [CrossRef]

46. Huff, A.C.; Kreuzer, K.N. Evidence for a common mechanism of action for antitumor and antibacterial agents that inhibit type II DNA topoisomerases. J. Biol. Chem. 1990, 265, 20496-20505.

47. Kwan, B.W.; Chowdhury, N.; Wood, T.K. Combatting bacterial infections by killing persister cells with mitomycin C. Environ. Microbiol. 2015, 17, 4406-4414. [CrossRef] 
48. Yeo, W.S.; Arya, R.; Kim, K.K.; Jeong, H.; Cho, K.H.; Bae, T. The FDA-approved anti-cancer drugs, streptozotocin and floxuridine, reduce the virulence of Staphylococcus aureus. Sci. Rep. 2018, 8, 2521. [CrossRef]

49. Woo, S.G.; Lee, S.Y.; Lee, S.M.; Lim, K.H.; Ha, E.J.; Eom, Y.B. Activity of novel inhibitors of Staphylococcus aureus biofilms. Folia Microbiol. 2017, 62, 157-167. [CrossRef]

50. Vik, A.; Hedner, E.; Charnock, C.; Samuelsen, O.; Larsson, R.; Gundersen, L.L.; Bohlin, L. (+)-agelasine D: Improved synthesis and evaluation of antibacterial and cytotoxic activities. J. Nat. Prod. 2006, 69, 381-386. [CrossRef]

51. Torres, N.S.; Abercrombie, J.J.; Srinivasan, A.; Lopez-Ribot, J.L.; Ramasubramanian, A.K.; Leung, K.P. Screening a Commercial Library of Pharmacologically Active Small Molecules against Staphylococcus aureus Biofilms. Antimicrob. Agents Chemother. 2016, 60, 5663-5672. [CrossRef] [PubMed]

52. Niu, H.; Yee, R.; Cui, P.; Tian, L.; Zhang, S.; Shi, W.; Sullivan, D.; Zhu, B.; Zhang, W.; Zhang, Y. Identification of Agents Active against Methicillin-Resistant Staphylococcus aureus USA300 from a Clinical Compound Library. Pathogens 2017, 6, 44. [CrossRef] [PubMed]

53. Lau, Q.Y.; Tan, Y.Y.; Goh, V.C.; Lee, D.J.; Ng, F.M.; Ong, E.H.; Hill, J.; Chia, C.S. An FDA-Drug Library Screen for Compounds with Bioactivities against Meticillin-Resistant Staphylococcus aureus (MRSA). Antibiotics 2015, 4, 424-434. [CrossRef]

54. Xu, J.; Pachon-Ibanez, M.E.; Cebrero-Cangueiro, T.; Chen, H.; Sanchez-Cespedes, J.; Zhou, J. Discovery of niclosamide and its O-alkylamino-tethered derivatives as potent antibacterial agents against carbapenemase-producing and/or colistin resistant Enterobacteriaceae isolates. Bioorganic Med. Chem. Lett. 2019, 29, 1399-1402. [CrossRef] [PubMed]

55. Gwisai, T.; Hollingsworth, N.R.; Cowles, S.; Tharmalingam, N.; Mylonakis, E.; Fuchs, B.B.; Shukla, A. Repurposing niclosamide as a versatile antimicrobial surface coating against device-associated, hospital-acquired bacterial infections. Biomed. Mater 2017, 12, 045010. [CrossRef] [PubMed]

56. Manner, S.; Vahermo, M.; Skogman, M.E.; Krogerus, S.; Vuorela, P.M.; Yli-Kauhaluoma, J.; Fallarero, A.; Moreira, V.M. New derivatives of dehydroabietic acid target planktonic and biofilm bacteria in Staphylococcus aureus and effectively disrupt bacterial membrane integrity. Eur. J. Med. Chem. 2015, 102, 68-79. [CrossRef] [PubMed]

57. Bollini, S.; Herbst, J.J.; Gaughan, G.T.; Verdoorn, T.A.; Ditta, J.; Dubowchik, G.M.; Vinitsky, A. High-throughput fluorescence polarization method for identification of FKBP12 ligands. J. Biomol. Screen. 2002, 7, 526-530. [CrossRef]

(C) 2020 by the authors. Licensee MDPI, Basel, Switzerland. This article is an open access article distributed under the terms and conditions of the Creative Commons Attribution (CC BY) license (http://creativecommons.org/licenses/by/4.0/). 